\title{
USV $\begin{aligned} & \text { Universidad } \\ & \text { de Granada }\end{aligned}$
}

TRABAJO FIN DE MASTER

“OPTIMIZACIÓN DE LOCALIZACIÓN DE SENSORES PARA IDENTIFICACIÓN ESTRUCTURAL MEDIANTE ANÁLISIS MODAL OPERACIONAL DEL PUENTE ARCO SOBRE EL RÍO GUADALQUIVIR EN LA A-453, PALMA DEL RÍO (CÓRDOBA)"

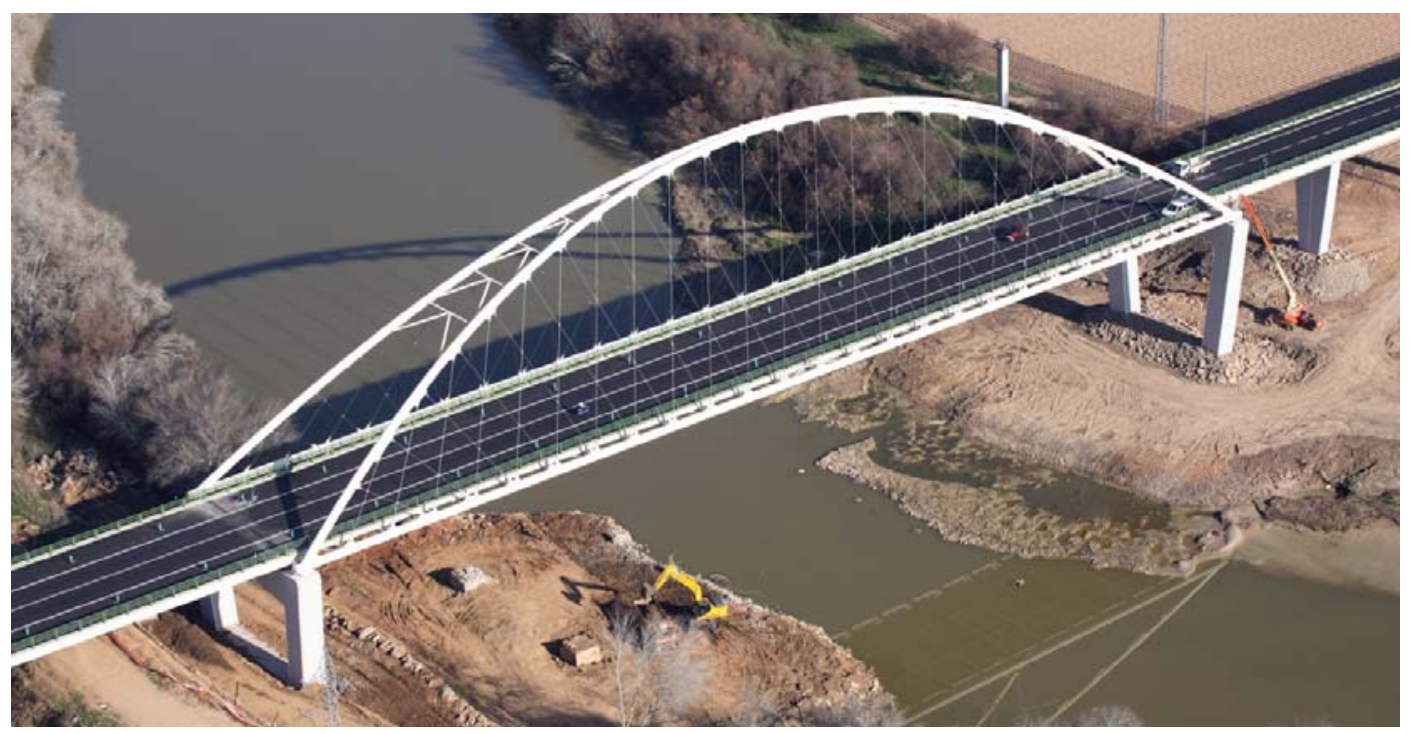

Alumno: Juan Carlos Fernández Sánchez

Septiembre de 2012

\section{Máster en Ingeniería de Estructuras}

Departamento de Mecánica de Estructuras e Ingeniería Hidráulica

Universidad de Granada

Tutor: Rafael Castro Triguero 


\section{Indice}

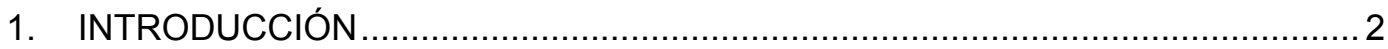

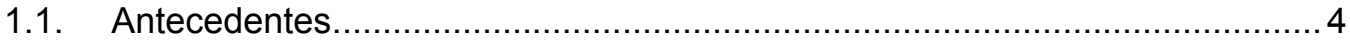

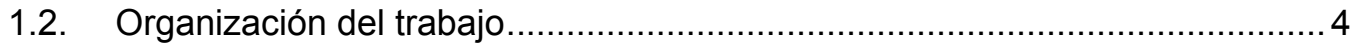

2. DESCRIPCIÓN DEL NUEVO PUENTE SOBRE EL RIO GUADALQUIVIR ........... 5

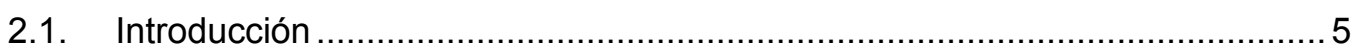

2.2. Esquemas característicos del Puente ........................................................ 7

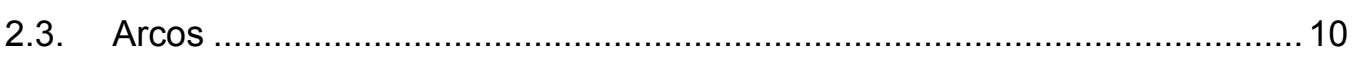

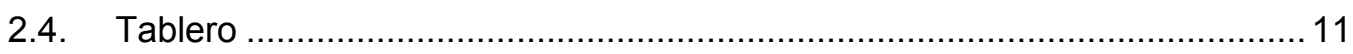

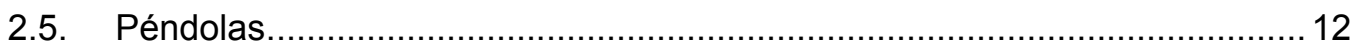

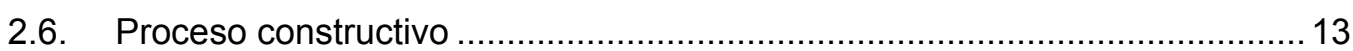

2.7. Detalles de los dispositivos de cruce de péndolas .................................... 16

2.8. Principales participantes en el proyecto ................................................ 17

3. DESCRIPCIÓN DEL MODELO Y ANÁLISIS NUMÉRICO .............................. 18

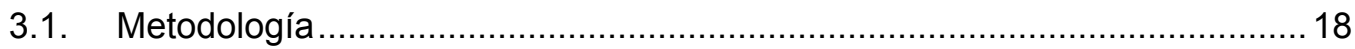

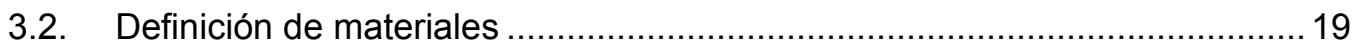

3.3. Definición geométrica de los elementos estructurales .............................20

3.3.1. Viga en doble $\mathrm{T}$ de sección variable del tablero................................. 21

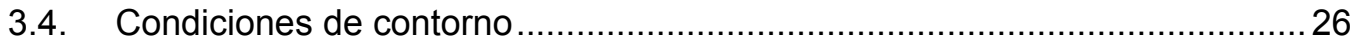

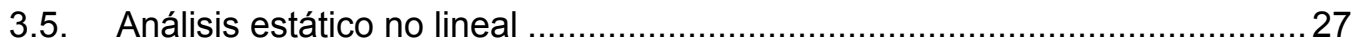

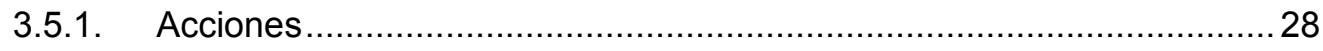

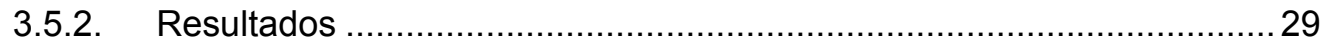

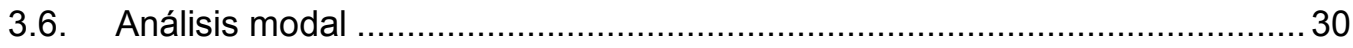

4. METODOLOGÍA DE OPTIMIZACIÓN DE LOCALIZACIÓN DE SENSORES......40

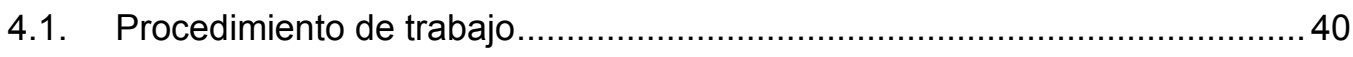

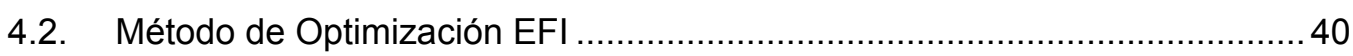

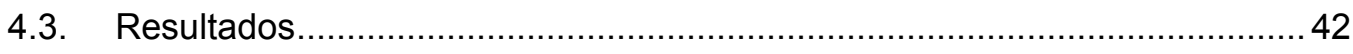

5. CONCLUSIONES Y TRABAJOS FUTUROS ........................................... 44

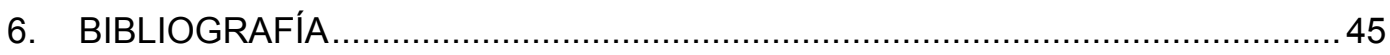




\section{INTRODUCCIÓN}

Dada el número, importancia y responsabilidad de las redes de infraestructuras (red de transporte de energía eléctrica, red ferroviaria, red de carreteras...) se hace necesario un plan de mantenimiento que garantice su estado de servicio, pues con el tiempo cambian sus condiciones de uso, las exigencias normativas, y por tanto puede llegar a producirse el deterioro o pérdida de seguridad de las mismas. El objetivo del mantenimiento Estructural Predictivo (MEP) consiste en la detección de fallos o daños estructurales en su fase prematura, de tal modo que una reparación a tiempo evite consecuencias más desastrosas desde el punto de vista económico o social.

El Análisis Modal Operacional (OMA) consiste en la identificación de los parámetros modales de una estructura en estado de servicio sin tener que interrumpir el mismo, y por medio de datos experimentales medidos in-situ. Los parámetros modales que se identifican son:

- Frecuencias naturales de vibración

- Coeficientes de amortiguamiento

- Modos de vibración

Por esta razón, el OMA se presenta como una de las técnicas fundamentales dentro del MEP. A partir del OMA y empleando técnicas de Actualización de Modelos, se pueden construir herramientas que muestren el comportamiento real de cada estructura durante su vida útil. Estas herramientas permitirán a su vez la identificación y caracterización del daño estructural, posibilitando la toma de decisiones sobre reparación y/o sustitución de elementos estructurales dañados, que es la finalidad del MEP.

La diferencia entre el Análisis Modal Operacional y el Experimental, es que en éste último los datos experimentales se toman en un laboratorio a partir de un modelo de ensayo y como resultado de cargas bien controladas. Dentro de las estrategias de OMA, el empleo de métodos de identificación de sistemas estructurales y de actualización de modelos de elementos finitos podrá identificar daños reales in-situ y no en laboratorio; entendiendo por daño cualquiera de los siguientes cambios producidos en:

- La configuración geométrica de la estructura

- Las propiedades mecánicas del material utilizado en su construcción 
- Las condiciones de sustentación

- Conectividad entre los diversos elementos individuales de la estructura

Los métodos empleados en la identificación de los sistemas estructurales dependen del tipo de datos captados en campo. Estos datos pueden consistir en señales de entrada y salida (input-output modal identification) o sólo en señales de salida (output-only modal identification). A partir de los datos que se obtengan en la monitorización de la estructura, se procederá a evaluar:

- La existencia de daño estructural

- Localización del posible daño

- Tipificación del daño

- Evaluación de la gravedad del daño

Las técnicas que utilizan señales de entrada y salida basan la identificación modal analizando la respuesta (salida) de la estructura real ante una fuerza (entrada) que se le aplica de forma controlada. El problema principal de tales técnicas en estructuras de puentes, líneas eléctricas, edificios o presas, reside en la gran dificultad de excitar los modos de vibración más significativos en un rango de frecuencias bajo con la energía suficiente y de forma controlada. En grandes estructuras flexibles, como puentes suspendidos por cables o atirantados, la fuerza de excitación requiere equipos extremadamente pesados y caros, los cuales no suelen estar disponibles en la mayoría de los laboratorios de dinámica de estructuras.

La alternativa a estos métodos son los que sólo utilizan la respuesta (salida) de la estructura provocada por el ruido ambiental como el viento o el tráfico. Esto es posible gracias a los recientes avances tecnológicos que han evolucionado hacia nuevos tipos de acelerómetros y conversores A/D (Analógico/Digital) más sensibles. Con este nuevo instrumental es posible medir de forma precisa niveles muy bajos de respuesta producida por ruidos ambientales. Lo que también supone que no requieren la interrupción del servicio de la estructura al tomarse las medidas durante el funcionamiento de la misma. Esto ha favoreciendo, a su vez, el desarrollo y evolución de métodos de identificación modal que emplean exclusivamente datos de salida (output-only modal identification). 


\subsection{Antecedentes}

Actualmente, los investigadores utilizan el Análisis Modal Operacional en la identificación de puentes de ferrocarril y carretera de cara a establecer planes para el mantenimiento de los mismos. Desde este Trabajo Fin de Máster se aborda el análisis númerico de un puente arco atirantado en Palma del Rio, así como la optimización de los recursos empleados en la monitorización y trabajos de campo requeridos.

Resulta fundamental desarrollar una metodología que optimice los recursos materiales a la hora de realizar los trabajos de identificación del daño pues de esa forma también se ahorrarán costes en los mismos. De esta forma, se propone una metodología de optimización para la localización de los sensores empleados en esos trabajos de identificación estructural que permitirá obtener la máxima información posible de las propiedades dinámicas de la estructura para un determinado número de sensores disponibles, lo que supone un ahorro tanto por el menor número de acelerómetros adquiridos como por la rapidez de los trabajos de campo. El método empleado en este trabajo es el Método EFI (Effective Independence Method - Método de la Independencia Efectiva sin ningún tipo de ponderación).

\subsection{Organización del trabajo}

El presente trabajo se estructura de la siguiente forma:

- En el Capítulo 2 se expone una descripción sobre el nuevo Puente Arco sobre el río Guadalquivir.

- En el Capítulo 3 se realiza una descripción de los modelos de elementos finitos empleados y análisis numérico del mismo.

- En el Capítulo 4 se desarrolla la metodología de Optimización de Localización de Sensores para la identificación estructural de viaductos mediante Análisis Modal Operacional.

- En el Capítulo 5 se exponen las conclusiones y posibles trabajos futuros.

- Por último en el Capítulo 6 se incluye la bibliografía empleada en el trabajo. 


\section{DESCRIPCIÓN DEL NUEVO PUENTE SOBRE EL RIO GUADALQUIVIR}

\subsection{Introducción}

El nuevo Puente Arco sobre el río Guadalquivir se encuentra en la nueva variante de Palma del Río (Córdoba) recientemente construida por GIASA. El proyecto debía plantear una solución singular sobre el río Gadalquivir, priorizando, la estética e integración paisajística de la solución. El viaducto que finalmente se ejecutó fue un puente arco metálico atirantado (tipo bowstring) de $130 \mathrm{~m}$ de luz con un tablero inferior mixto.

La estructura portante principal está constituida por dos arcos atirantados inclinados laterales en perfiles tubulares de acero S355-J2G3, de $90 \mathrm{~cm}$ de diámetro, tanto para el arco como para el tirante, y espesores de chapa máximos de $50 \mathrm{~mm}$ en los arranques de los arcos. La extrema esbeltez de arco y tirantes (C/L =1/144.4) se consigue gracias a un sistema de péndolas inclinadas con múltiples cruces y cables cerrados, tipo Network que minimiza drásticamente las flexiones en arco y tirante así como los efectos del pandeo en el arco.

Los múltiples cruces entre péndolas se resolvieron con un original dispositivo que permitía ordenar el esquema de cables y minimizar el impacto visual de los citados cruces.

En este tipo de puentes, todas las cargas que actúan sobre el tablero son soportadas por las péndolas que a su vez las transmiten a los arcos superiores. Desde los arcos, las cargas desciende hacía los puntos de apoyos donde la componente vertical de esta carga se transmite a las pilas y la cimentación, y la componente horizontal tracciona el tablero del puente, actuando como tirante del arco.

Se encuentra situado dentro de una recta que desciende con pendiente constante del $0.83 \%$. La anchura total de la plataforma del puente es de $16 \mathrm{~m}$., Inicialmente esta anchura se repartirá en dos carriles de $3.5 \mathrm{~m}$ centrales, dos arcenes de $4.0 \mathrm{~m}$, y dos barreras laterales de $0.5 \mathrm{~m}$ cada una. Posteriormente, y cuando se amplíe la capacidad de la vía, la anchura pasará a repartirse de la siguiente forma: 4 carriles centrales de $3.5 \mathrm{~m}$, dos arcenes de $0.5 \mathrm{~m}$, y dos barreras laterales de $0.5 \mathrm{~m}$ cada una. 
La condición básica de salvar el río Guadalquivir sin colocar pilas dentro del cauce, obligaba a plantear soluciones de luces en el tramo principal del puente entre 120 y $140 \mathrm{~m}$. Bajo esta condición, dos fueron los factores principales que condicionaron el posicionamiento del puente.

El primero de ellos, fue el tratar de mantener el puente centrado respecto el cauce. Esta condición, que a priori parece evidente, no lo es si tenemos en cuenta que el perfil de las márgenes derecha e izquierda del río son muy diferentes. Mientras que el margen derecho (lado norte) presenta unas pendientes pronunciadas con una variación de altura de unos $10 \mathrm{~m}$ en $25 \mathrm{~m}$ de longitud, el margen izquierdo (lado sur) tiene pendientes muy suaves que ganan lentamente altura a medida que nos alejamos del río y penetramos en la vega. Resulta imposible realizar un encaje simétrico del puente respecto el río para todas las posibles cotas de agua, por lo que se trató de encajar la solución para el nivel de aguas medias.

La segunda condición venía impuesta por la elevada altura que presenta la rasante en su cruce sobre el río por la necesidad de salvar el cruce con la carretera $\mathrm{N}$ 431 y con las vías de ferrocarril, con gálibo suficiente, y que determinan un valor medio de altura de pilas de aproximadamente $20 \mathrm{~m}$. Dado que las características geotécnicas del terreno no son buenas, y que nos encontramos en una zona donde es necesario considerar los efectos derivados de las acciones sísmicas, resultaba muy conveniente reducir la altura de las pilas al máximo posible para no encarecer el coste de éstas y sus cimentaciones. Aprovechando que la margen derecha del río gana rápidamente altura, se desplazó ligeramente el vano central hacía este lado con el fin de disminuir la altura de la pila de apoyo en este punto y materializar en ella, el punto fijo frente a movimientos horizontales del tablero. 


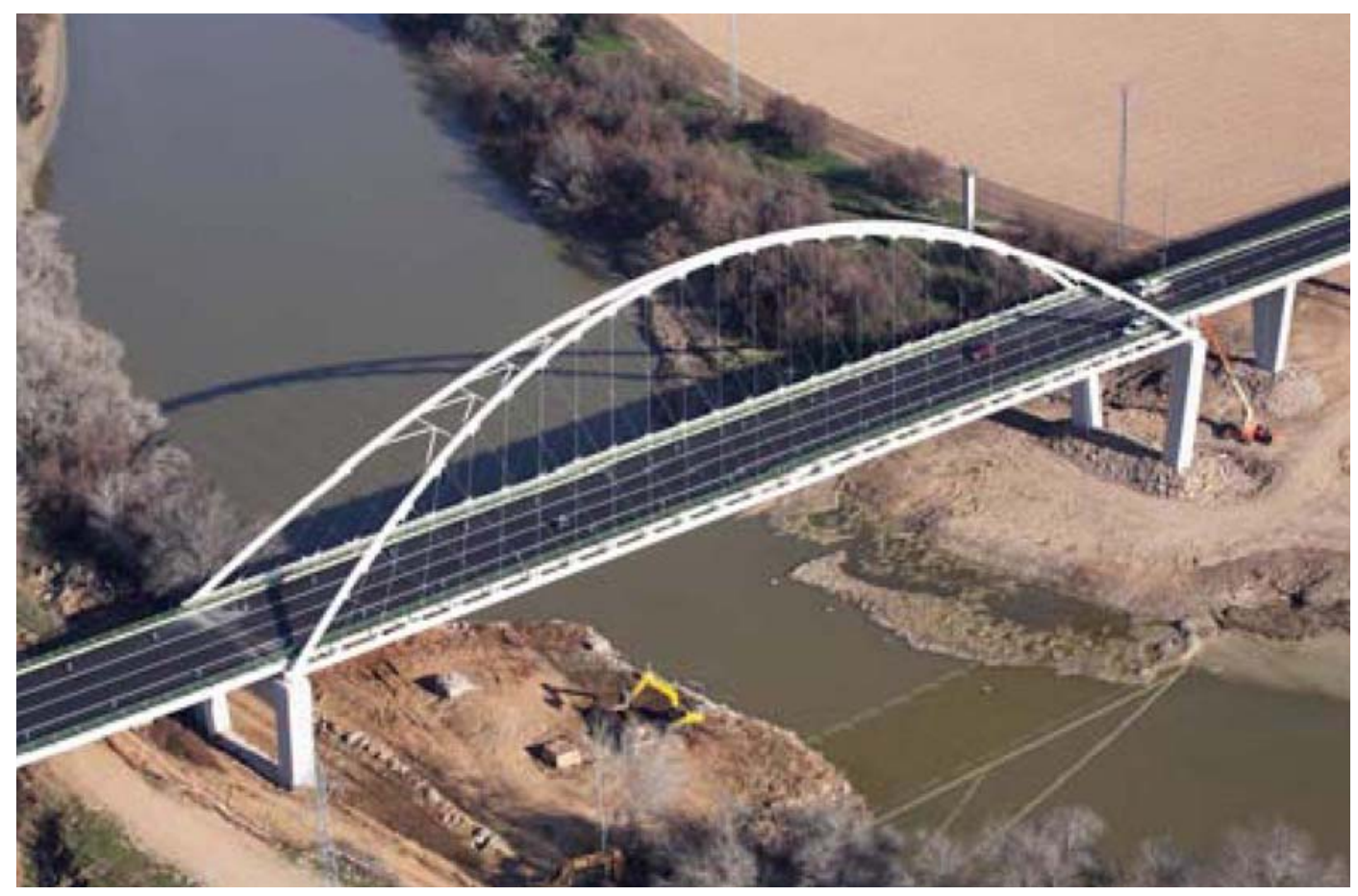

Fig.1: Vista aérea del Puente Arco sobre el Río Guadalquivir

La tipología escogida para el tramo central fue la de doble arco simétrico con $130 \mathrm{~m}$ de luz, situando cada arco en un plano inclinado $68.8^{\circ}$ respecto de la vertical y apoyados entre sí en clave (Fig. 1). Con esta solución se perseguía a la vez que dotar a la estructura de un especial dinamismo y originalidad, reducir la longitud de pandeo de cada uno de los arcos disponiendo el menor número de arriostramientos transversales entre ellos.

El funcionamiento estructural es completamente similar al de un arco situado en un plano vertical, con un único efecto añadido en los extremos, donde es necesario equilibrar la componente de fuerza horizontal en sentido transversal al eje del puente que genera la inclinación de los arcos.

\subsection{Esquemas característicos del Puente}

En las siguientes figuras se representa la planta, alzado y sección transversal del Puente Arco sobre el Río Guadalquivir (Figs. 2 y 3): 


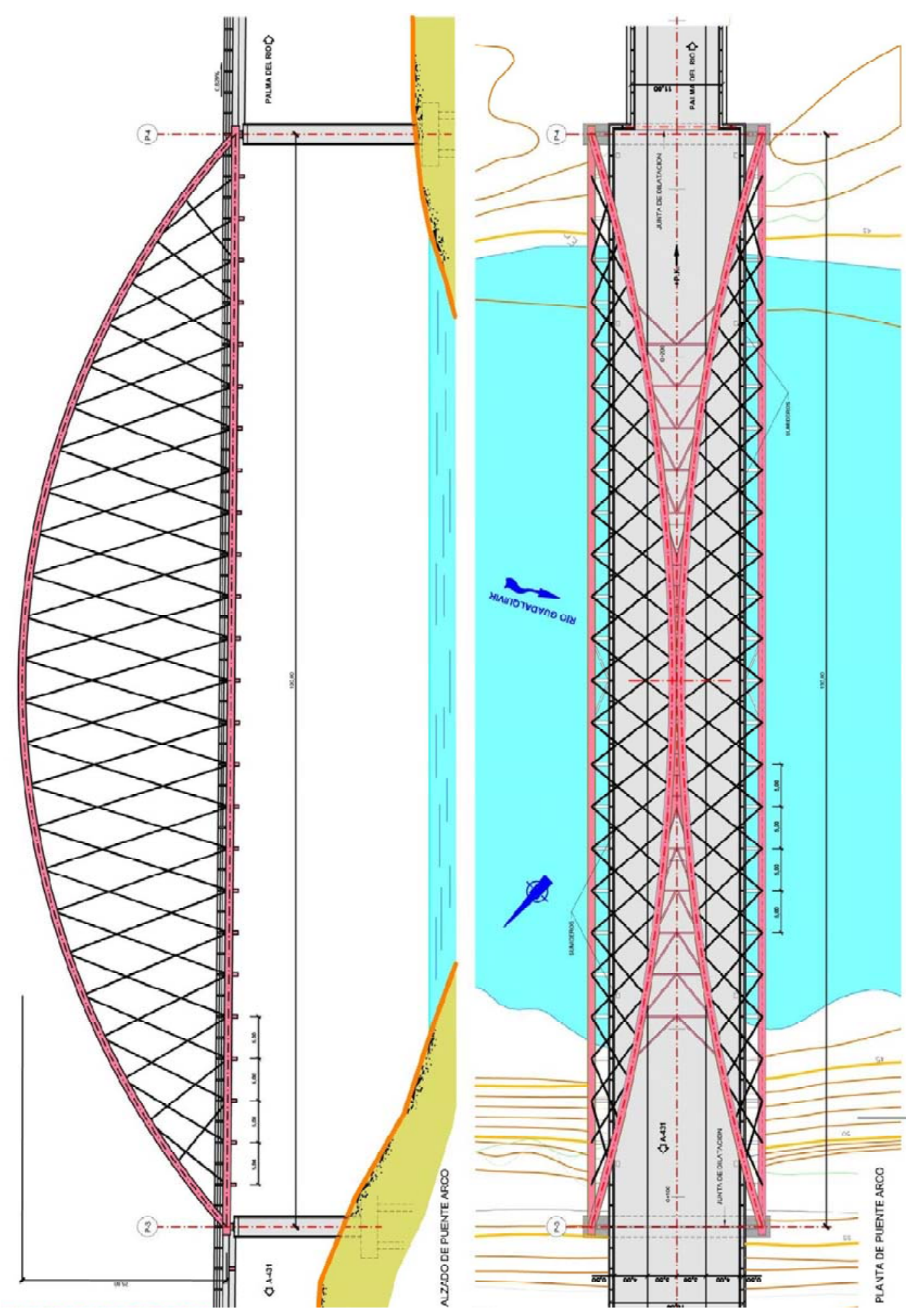

Fig. 2: Planta y Alzado del Puente Arco sobre el Río Guadalquivir. Proyecto de Construcción [6] 


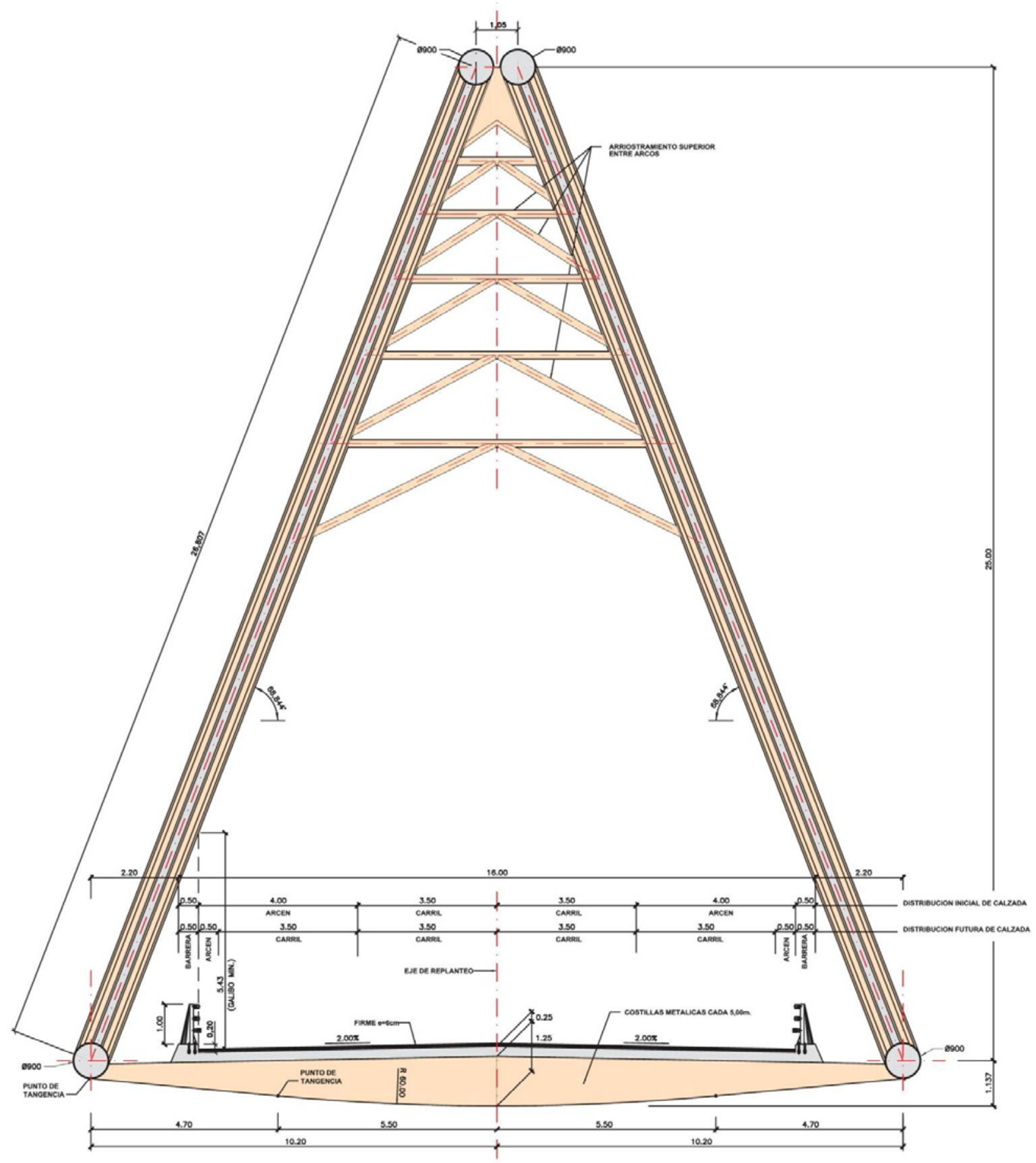

Fig. 3: Sección Transversal del Puente Arco sobre el Río Guadalquivir Proyecto de Construcción [6] 


\subsection{Arcos}

Como sección transversal para los arcos (Fig. 3), se optó por perfiles tubulares de sección constante y $90 \mathrm{~cm}$ de diámetro buscando la mayor sencillez de formas a la vez que de fabricación.

La directriz que se planteó fue parabólica, antifunicular de las cargas permanentes en el arco, con una flecha en clave de $25 \mathrm{~m}$, con lo que la relación flecha - luz es de 1/5,2 (Figs. 3 y 4 ).

A lo largo de los arcos y cada $5 \mathrm{~m}$ se disponen los puntos de anclajes con las péndolas.

Uniendo entre sí los arcos, se dispuso un arriostramiento en celosía en "K" formada por perfiles tubulares, igual que en el arco, y que permitían acotar la longitud de pandeo de los arcos (Fig. 4).

El acero de los arcos es S 355 J2G3.

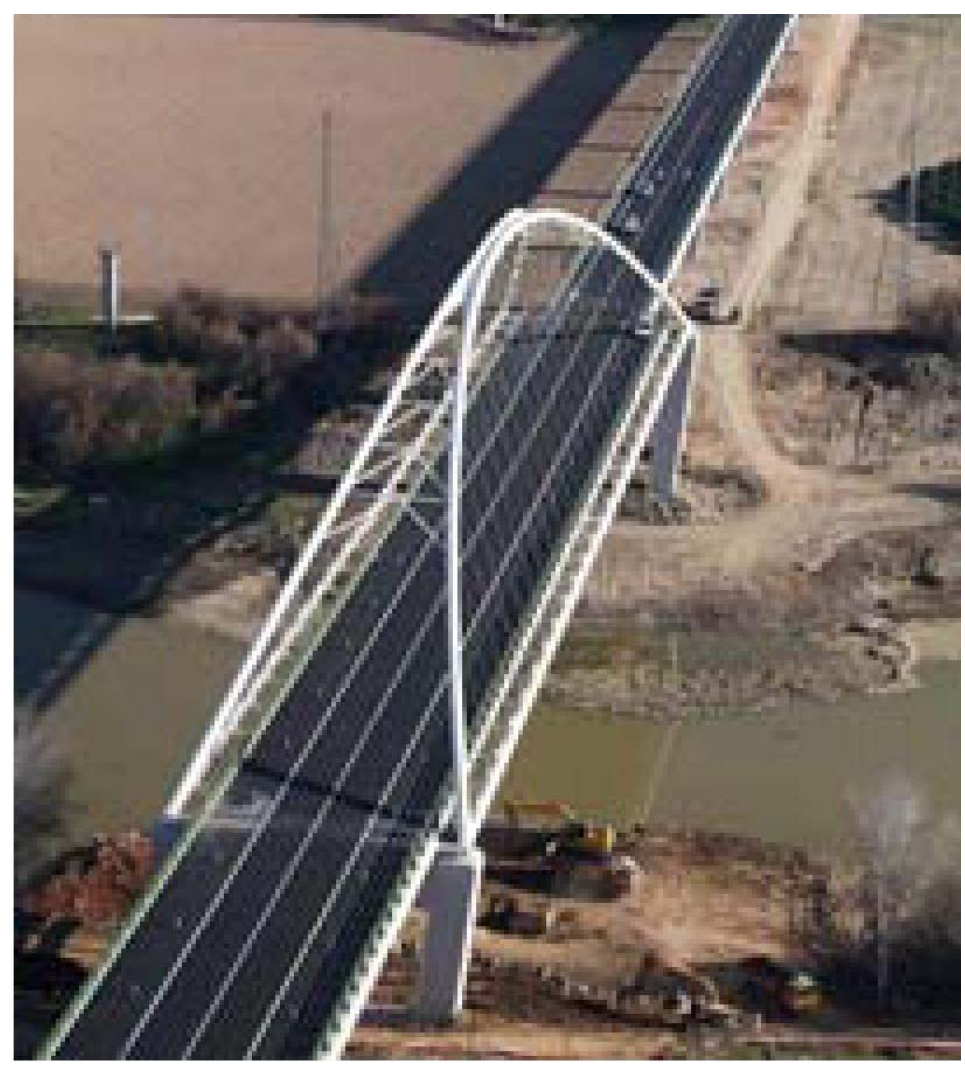

Fig. 4: Vista aérea frontal del Puente Arco sobre el Río Guadalquivir 


\subsection{Tablero}

El tablero del puente de $16 \mathrm{~m}$ de ancho está formado por una losa de $0.25 \mathrm{~m}$ de espesor constante, con inclinación del $2 \%$ hacia ambos bordes de la calzada. Esta losa se ejecuta en dos partes. La primera, formada por una prelosa prefabricada que se coloca apoyada sobre las vigas transversales que existen cada $5 \mathrm{~m}$, y que sirve como encofrado perdido para la ejecución del resto de la losa del tablero. La segunda, se materializa al colocar la ferralla correspondiente y verter hormigón "in situ" sobre la primera hasta completar el espesor total.

La losa del puente se apoya sobre las vigas transversales metálicas situadas cada $5 \mathrm{~m}$. Estas vigas tienen una luz total de $20.4 \mathrm{~m}$ (Fig. 3), y se apoyan en los tirantes tubulares laterales que discurren de extremo a extremo del puente. En los mismos puntos de apoyo de las vigas transversales se disponen los puntos de anclaje de las péndolas (Figs. $5 a$ y $5 \mathrm{~b}$ ) que unen el tablero con los arcos superiores. De esta forma, los tirantes laterales, no se ven sometidos a los efectos de las cargas puntuales que actúan sobre el tablero.
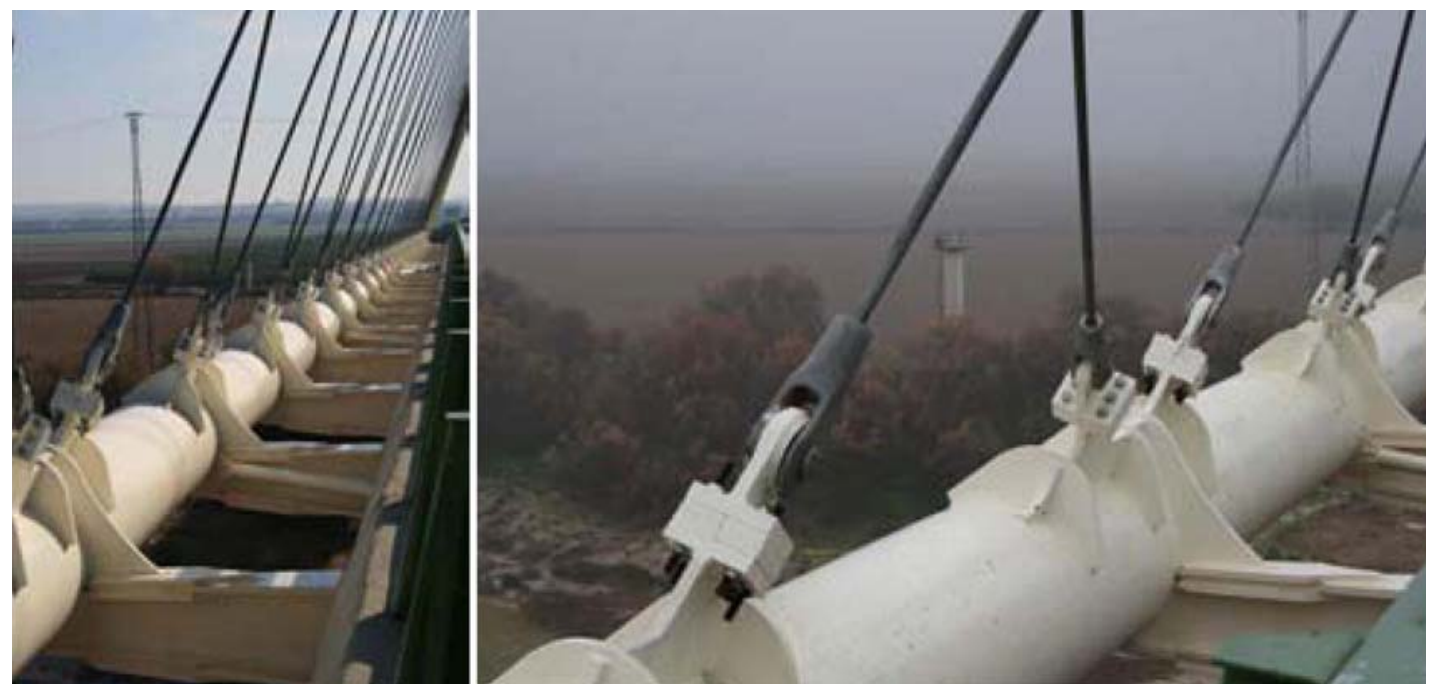

Figs. 5a y 5b: Detalles de anclajes de péndolas inferiores y arranques de vigas transversales dispuestas cada $5 \mathrm{~m}$ en el tablero

Las vigas transversales (Fig. 6) tienen canto variable, siguiendo el fondo de la viga una curva circular de radio $60 \mathrm{~m}$ en su parte central, y con variación lineal en el resto, coincidente con la geometría empleada en las secciones de los viaductos de acceso, y con un canto máximo en el centro de la sección de $1.25 \mathrm{~m}$. La sección transversal tiene forma de doble " $T$ ". 


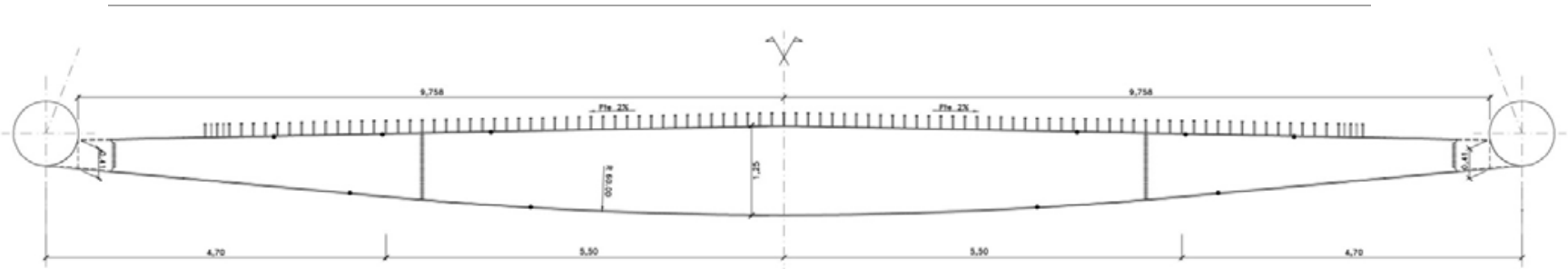

Fig. 6: Detalle de una viga trasversal tipo del tablero situada cada $5 \mathrm{~m}$.

En la platabanda superior de la viga, se disponen los conectadores necesarios para vincularla al hormigón de la losa superior, constituyendo transversalmente una viga mixta.

A 10.2 m del eje de la sección, se sitúan dos tubos metálicos laterales, los tirantes, de $90 \mathrm{~cm}$ de diámetro y de longitud igual a la de la luz del puente, $130 \mathrm{~m}$, en donde se apoyan las vigas transversales y en donde se realiza la unión de las péndolas de cuelgue del tablero.

La misión de estos tirantes es principalmente la de servir de tirante de tracción al arco, equilibrando la componente horizontal de la carga de los arcos en los extremos y evitando la transmisión de cargas horizontales a la cimentación, además de la ya reseñada de servir de punto de apoyo a las vigas transversales.

En el punto de unión de los arcos con los tirantes laterales del tablero, se dispone la riostra transversal de apoyo, con una geometría similar a la de las vigas transversales, la cual debe recoger la componente horizontal transversal generada debido a la inclinación de los arcos, y que constituye un punto básico de la estructura para garantizar el equilibrio del conjunto.

Dado que la inercia a flexión de los tirantes es reducida, apenas si tienen capacidad para recoger flexiones, obligando a que este trabajo se realice mediante la transmisión de cargas al arco.

El acero empleado en las vigas del tablero así como en los tubos de los arcos y tirantes es S $355 \mathrm{~J} 2 \mathrm{G} 3$. El hormigón in situ empleado en el tablero es HA30/B/20/IIb.

\subsection{Péndolas}

Las péndolas actúan como elemento de unión entre el tablero y el arco, transmitiendo las cargas del primero al segundo. La disposición de las péndolas es en celosía o malla triangulada tipo Network, según Millanes [4], existiendo dos planos de 
péndolas, cada uno de los cuales parte de uno de los tubos laterales del tablero hasta el arco correspondiente.

Los puntos de anclajes inferiores se sitúan cada $5 \mathrm{~m}$, sobre los tubos laterales, y de cada punto parten dos péndolas hasta su encuentro con el arco, también con la cadencia de $5 \mathrm{~m}$.

El sistema de péndolas con múltiples cruces en la tipología Network, hace que el puente se comporte como una gran viga de canto igual a la flecha de los arcos con capacidad para transmitir cortantes, además de reducir los momentos flectores en arco y tablero para las hipótesis de carga en medio vano, frente a los que se obtendrían en una solución de péndolas verticales. Además, con esta disposición se logra una gran capacidad de reparto de las acciones de las carga puntuales, reduciendo las flexiones sobre el tablero al mínimo.

Por otra parte, al aumentar el número de péndolas permite la colocación de unidades de pequeño tamaño, más fáciles de disponer y colocar.

La distancia entre anclajes de tirantes es reducida, $5 \mathrm{~m}$, con lo que se conseguían múltiples objetivos:

- Reducir la longitud de pandeo de los arcos.

- Reducir los esfuerzos flectores en el tablero.

- Simplificar las uniones arco - tirante y tablero - tirante al emplear unidades de pequeño tamaño.

- Lograr una gran eficacia en el reparto de las cargas puntuales en el tablero.

\subsection{Proceso constructivo}

El material que se propuso para la realización del puente fue el acero. Para los arcos, si bien como primera idea se podría pensar en el hormigón, dado que los esfuerzos predominantes son de compresión, analizando el proceso constructivo se observó que se obtienen grandes ventajas del empleo del metal, cuyo montaje se puede realizar mediante la división de la longitud completa del arco en tramos y su posterior montaje y unión en obra mediante elementos auxiliares de relativa sencillez y en plazos más reducidos que la solución de hormigón.

El empleo del metal como material predominante permitió asimismo, reducir las reacciones sobre las cimentaciones y abaratar el coste de éstas. 
Para poder realizar el montaje de la estructura metálica fue necesario ejecutar sendas penínsulas artificiales en ambas márgenes del río, que permitían la colocación sobre ellas de apeos provisionales para realizar el montaje de la estructura metálica (Fig. 7). La cimentación de los apeos se pilotó para evitar las posibles socavaciones que pudieran acaecer por crecidas del río durante el proceso constructivo.

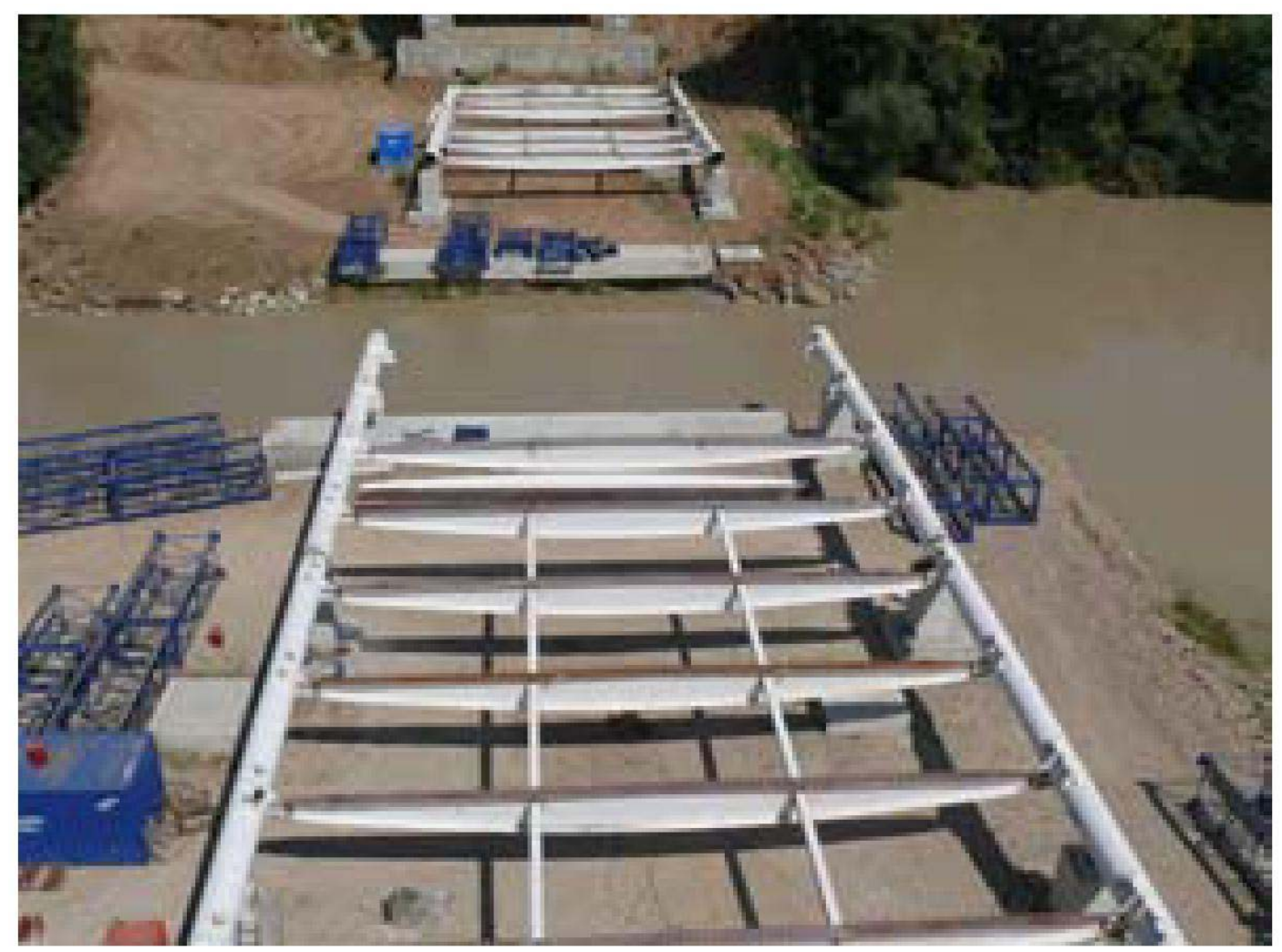

Fig. 7: Vista de las penínsulas artificales y de las labores de ensamblaje de la estructura metálica del tablero

El montaje de la estructura metálica comienza por la soldadura en obra de las vigas transversales a los tubos laterales del tablero (Fig. 7), hasta completar los tramos a izar, y el posterior izado mediante grúas hasta completar la totalidad del tablero (Figs. 8a y 8b). 

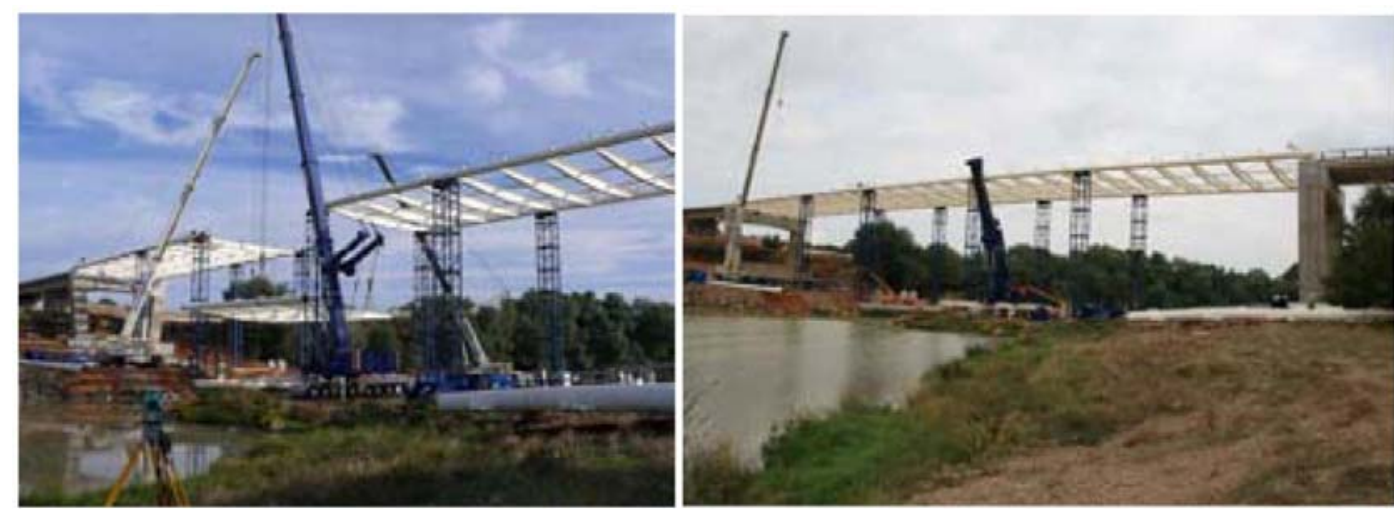

Figs. 8a y 8b: Izado de un tramo de tablero y vista del tablero metálico del puente concluido y apeado

Una vez finalizado el montaje del metal del tablero, se procede a montar los arcos, para lo cual se disponen 4 apeos dobles que servirán de apoyo temporal a los arcos superiores. A la vez a pie de obra se sueldan los arriostramientos transversales entre arcos. Una vez completadas estas operaciones, se izan mediante grúas cada uno de los tramos de los arcos, apoyándolos sobre los apeos (Figs. 9a y 9b).

Por último, se realiza la soldadura entre los tramos de los arcos y en los extremos al tablero y se desapean completamente los arcos, dejando la estructura metálica del tablero todavía apeada.

A continuación se colocan todas las péndolas uniendo el tablero con los arcos y se realiza la puesta en carga siguiendo el proceso de tesado definido en el proyecto. Completada esta fase, el tablero queda suspendido por las péndolas y ya se pueden retirar los apeos inferiores al ser la estructura metálica autorresistente.
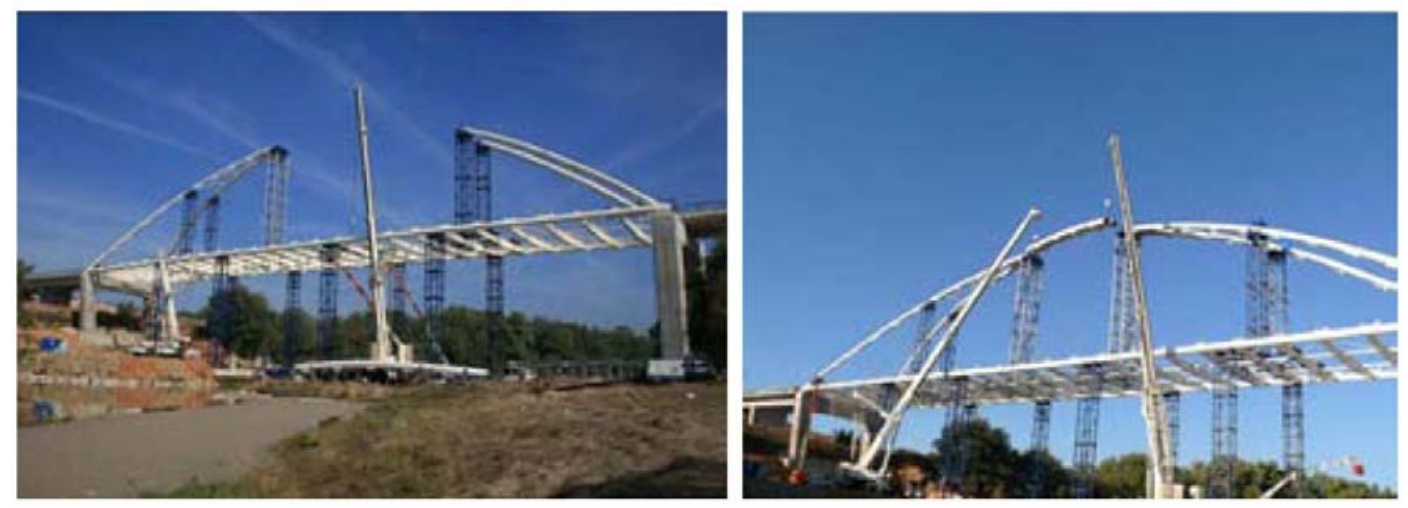

Figs. 9a y 9b: Vista durante las operaciones de izado de los arcos, y fase de cierre en clave de los arcos 
Con el tablero sustentado ya por las péndolas, se procede a la colocación mediante grúa de las prelosas del tablero y al ferrallado del tablero (Figs. 10a y 10b) y al hormigonado en una sola fase de la totalidad del tablero.

Para finalizar, se realizan los ajustes finales en las tensiones de las péndolas junto con las labores de acabado (colocación de imposta y barrera, impermeabilización, pavimentación y colocación de juntas) y la prueba de carga.
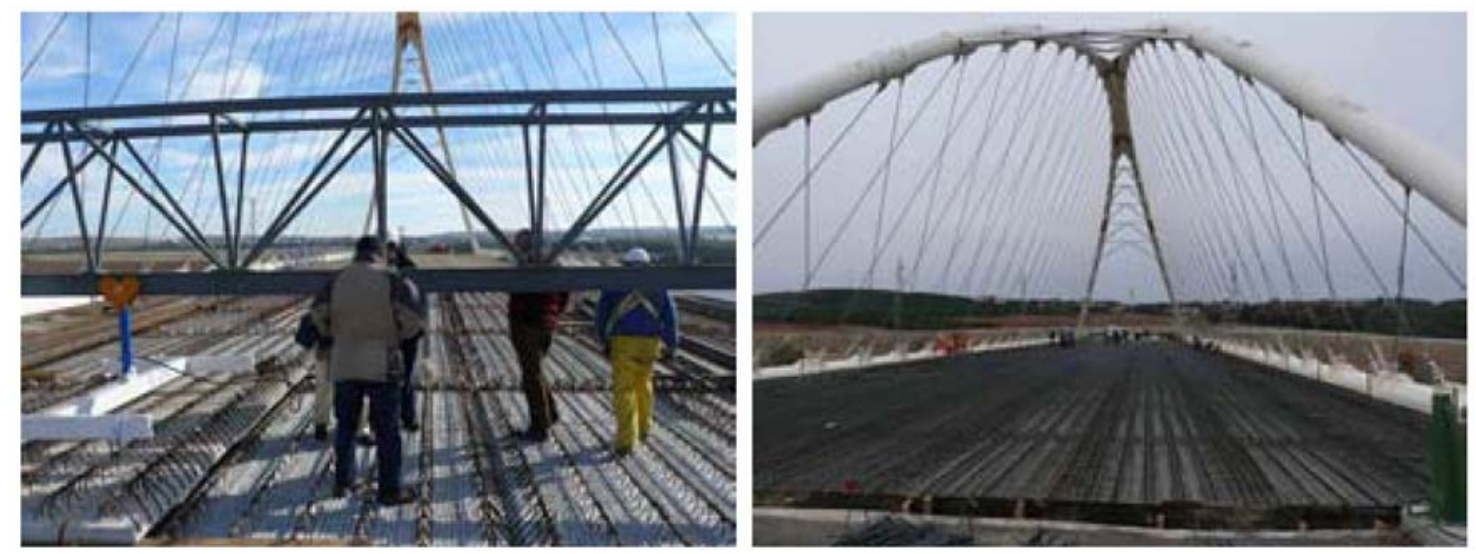

Figs. 10a y 10b: Vista durante las operaciones de colocación de prelosas en el tablero y con el tablero ferrallado

\subsection{Detalles de los dispositivos de cruce de péndolas}

El proyecto puso especial énfasis en el diseño, simple y ordenado, de las uniones entre péndolas y secciones tubulares de arco y tirante, de gran impacto visual, con detalles que, al mismo tiempo, conjugaban la facilidad constructiva y la eficacia resistente.

Las péndolas del Puente son cables cerrados de 45 y $55 \mathrm{~mm}$ de diámetro formando una malla inclinada por cada arco con múltiples cruces en la tipología Network. Cada una de las mallas se encuentra en dos planos diferentes cada uno de ellos con una ligera excentricidad de $50 \mathrm{~mm}$ respecto del plano del arco, por lo cual las péndolas se cruzan pero no se cortan. En el punto de cruce de dos péndolas se coloca un dispositivo formado por tres piezas que permite el libre giro de una respecto de la otras (Figs. 11a y 11b). 
En los extremos de cada péndola se dispone una rótula con un terminal a modo de horquilla que permite el libre giro del cable, tanto en su unión con los arcos, como con su unión con los tirantes del tablero.
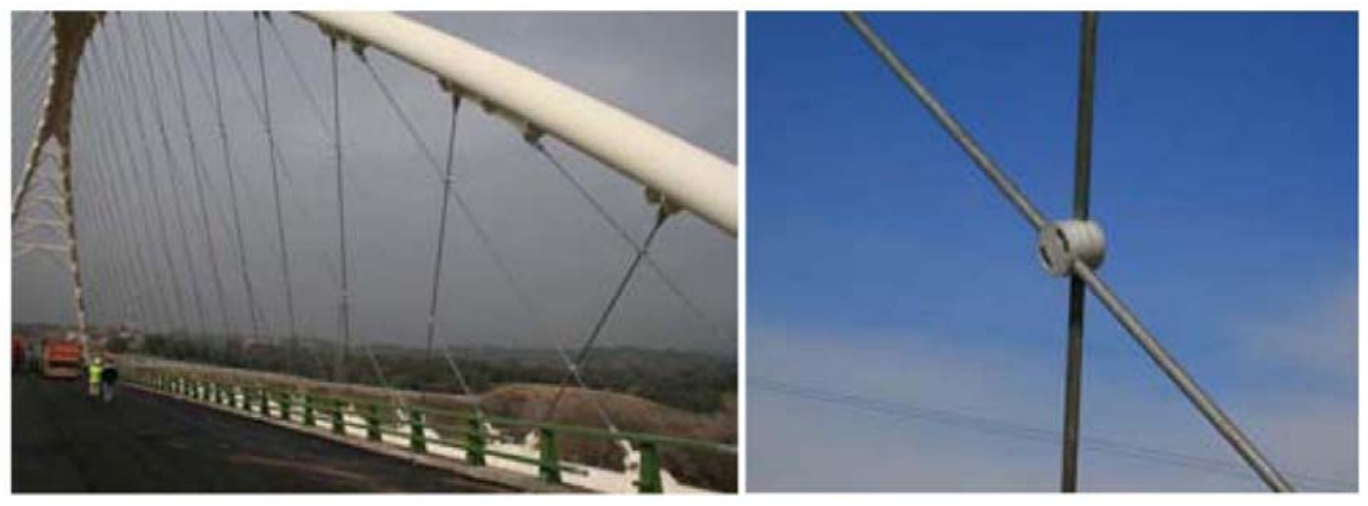

Figs. 11a y 11b: Detalle de pédolas en dos planos paralelos con los dispositivos de cruce de péndolas

\title{
2.8. Principales participantes en el proyecto
}

\author{
Propiedad: $\quad$ GIASA \\ Proyecto: $\quad$ UTE NARVAL-IDEAM \\ Francisco Millanes Mato, Miguel Angel de la Rúa López \\ Dirección de Obra: UTE NARVAL-IDEAM \\ Luis Gamboa Ramos, Francisco Jesús Ayala Escribano \\ Constructor: $\quad$ FCC Construcción S.A.
}




\section{DESCRIPCIÓN DEL MODELO Y ANÁLISIS NUMÉRICO}

\subsection{Metodología}

Se procede al análisis numérico mediante el método de los elementos finitos a través del software SAP2000 Advanced 14.1.0 para obtener los modos de vibración del Puente Arco.

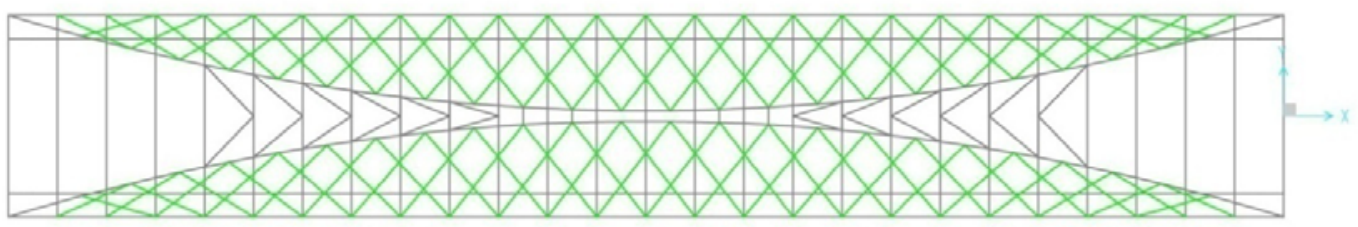

Fig. 12: Planta del modelo realizado en SAP2000

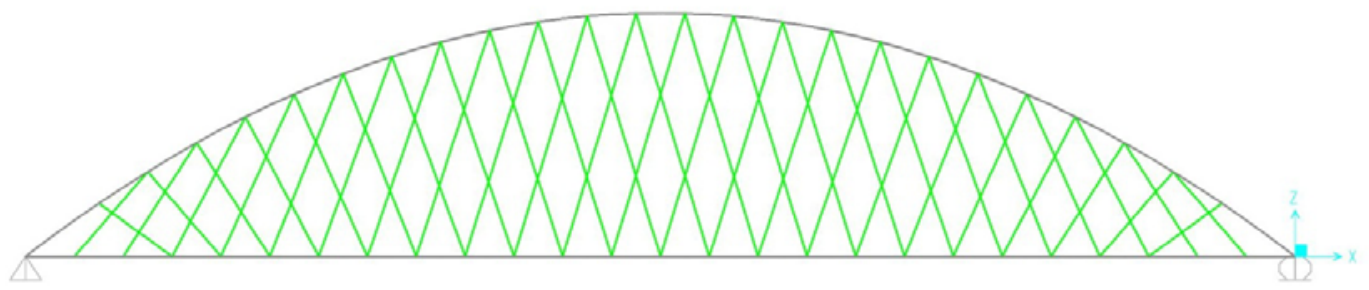

Fig. 13: Alzado del modelo realizado en SAP2000

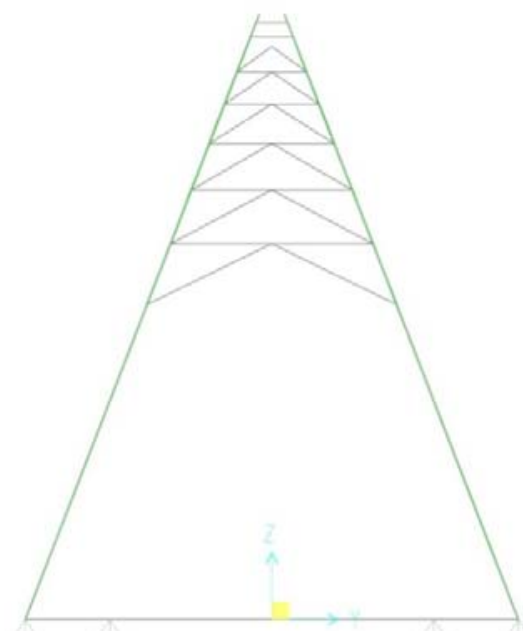

Fig. 14: Sección transversal del modelo realizado en SAP2000 


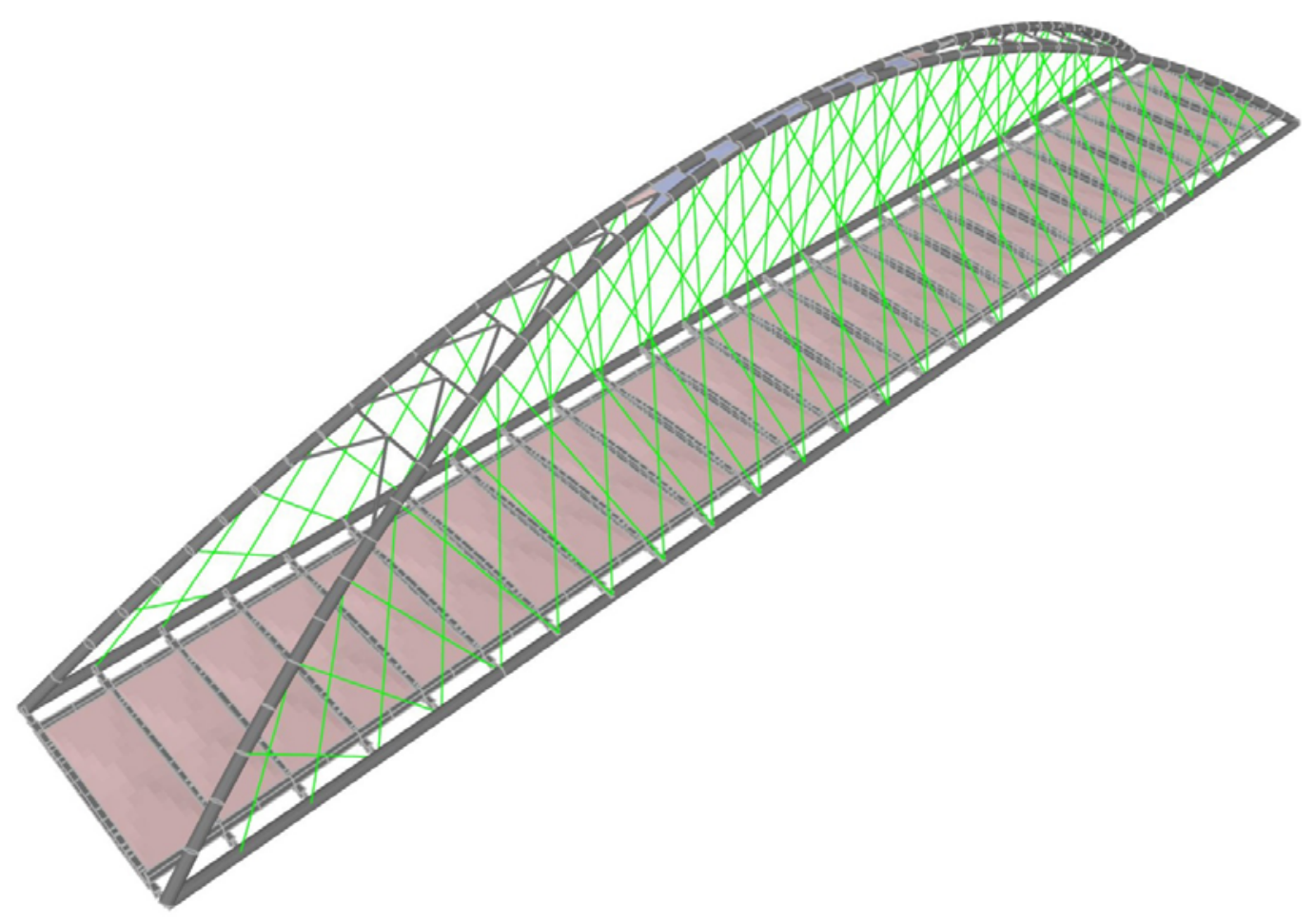

Fig. 15: Representación 3D del modelo realizado en SAP2000

\subsection{Definición de materiales}

Los materiales se han definido con los mismos parámetros utilizados en el Proyecto de Construcción [6]. A continuación se detallan los datos utilizados en el modelo:

Acero S 355 J2G3: Empleado en el acero estructural de las vigas del arco, tablero, costillas y rigidizadores.

- Módulo de elasticidad:

- Módulo de elasticidad transversal:

- Coeficiente de Poisson:

- Coeficiente de dilatación lineal:

- Densidad:

- Límite elástico:

$$
\begin{aligned}
& E=2,1 \cdot 10^{8} \mathrm{KN} / \mathrm{m}^{2} \\
& G=E /(2 \cdot(1+\mathrm{v}))=80.769 .231 \mathrm{KN} / \mathrm{m}^{2} \\
& v=0,3 \\
& \alpha=1,2 \cdot 10^{-5}{ }^{\circ} \mathrm{C}^{-1} \\
& \mathrm{~V}=7.850 \mathrm{Kg} / \mathrm{m}^{3} \\
& \text { fy }=355.000 \mathrm{KN} / \mathrm{m}^{2}
\end{aligned}
$$

Acero Y 1860 S7: Empleado en las péndolas. 
- Módulo de elasticidad:

$$
\begin{array}{ll}
\text { - Módulo de elasticidad: } & \mathrm{E}=1,95 \cdot 10^{8} \mathrm{KN} / \mathrm{m}^{2} \\
\text { - Módulo de elasticidad transversal: } & \mathrm{G}=\mathrm{E} /(2 \cdot(1+\mathrm{v}))=7,5 \cdot 10^{7} \mathrm{KN} / \mathrm{m}^{2} \\
\text { - Coeficiente de Poisson: } & \mathrm{v}=0,3 \\
\text { - Coeficiente de dilatación lineal: } & \alpha=1,2 \cdot 10^{-5}{ }^{\circ} \mathrm{C}^{-1}
\end{array}
$$$$
\text { - Coeficiente de Poisson: v } \quad v=0,3
$$$$
\text { - Densidad: } \quad \mathrm{Y}=7.850 \mathrm{Kg} / \mathrm{m}^{3}
$$

HA-30/B/20/llb: Empleado en la losa de $25 \mathrm{~cm}$. del tablero.

- Módulo de deformación longitudinal del hormigón:

$$
E_{c m}=8.500 \cdot f_{c m}^{1 / 3}=8.500 \cdot(30+8)^{1 / 3}=28.576 .000 \mathrm{KN} / \mathrm{m}^{2}
$$

- Módulo de elasticidad transversal: $\quad \mathrm{G}=\mathrm{E} /\left(2 \cdot(1+\mathrm{v})=11.906 .667 \mathrm{KN} / \mathrm{m}^{2}\right.$

- Coeficiente de Poisson: $\quad v=0,2$

- Coeficiente de dilatación lineal: $\quad \alpha=1 \cdot 10^{-5}{ }^{\circ} \mathrm{C}^{-1}$

- Densidad: $\quad y=2.550 \mathrm{Kg} / \mathrm{m}^{3}$

- Límite elástico: fy $=30.000 \mathrm{KN} / \mathrm{m}^{2}$

\subsection{Definición geométrica de los elementos estructurales}

El Puente se compone de los siguientes elementos estructurales:

- Arco (acero S 355 J2G3):

- Vigas tubulares de sección constante de $900 \mathrm{~mm}$. de diámetro y $50 \mathrm{~mm}$. de espesor.

- Vigas tubulares de sección constante de $900 \mathrm{~mm}$. de diámetro y $25 \mathrm{~mm}$. de espesor.

- Arriostramiento de las vigas del Arco (acero S 355 J2G3):

- Celosía en "K" con vigas tubulares de $219 \mathrm{~mm}$. de diámetro y $10 \mathrm{~mm}$. de espesor.

- Chapa de $20 \mathrm{~mm}$. de espesor.

- Tirantes del tablero (acero S 355 J2G3):

- Vigas tubulares de sección constante de $900 \mathrm{~mm}$. de diámetro y $40 \mathrm{~mm}$. de espesor.

- Vigas tubulares de sección constante de $900 \mathrm{~mm}$. de diámetro y $30 \mathrm{~mm}$. de espesor.

- Vigas transversales del tablero (acero S 355 J2G3):

- Viga en doble "T" con canto y espesores variables. Se vincula al hormigón de la losa superior y constituye transversalmente una viga mixta. 
- Losa superior del tablero (hormigón HA-30/B/20/llb):

- Placa de $25 \mathrm{~cm}$. de espesor.

- Péndolas (acero Y 1860 S7):

- Cables de $45 \mathrm{~mm}$. de diámetro.

- Cables de $55 \mathrm{~mm}$. de diámetro.

Los elementos finitos utilizados son los que mejor simulan el comportamiento de la estructura. A continuación se describe el tipo de elemento SAP2000 empleado para definir las distintas partes de la estructura:

Tabla 1: Descripción de los elementos utilizados en el modelo (SAP2000)

\begin{tabular}{|l|l|l|}
\hline Descripción del elemento & Material & $\begin{array}{l}\text { Tipo de elemento } \\
\text { SAP2000 }\end{array}$ \\
\hline $\begin{array}{l}\text { Vigas tubulares D900mm. y E50mm. } \\
\text { (arco) }\end{array}$ & Acero S 355 J2G3 & Frame Sections - Pipe \\
\hline $\begin{array}{l}\text { Vigas tubulares D900mm. y E25mm. } \\
\text { (arco) }\end{array}$ & Acero S 355 J2G3 & Frame Sections - Pipe \\
\hline $\begin{array}{l}\text { Vigas tubulares D900mm. y E40mm. } \\
\text { (tirante del tablero) }\end{array}$ & Acero S 355 J2G3 & Frame Sections - Pipe \\
\hline $\begin{array}{l}\text { Vigas tubulares D900mm. y E30mm. } \\
\text { (tirante del tablero) }\end{array}$ & Acero S 355 J2G3 & Frame Sections - Pipe \\
\hline $\begin{array}{l}\text { Viga en doble "T" con cantos y espesores } \\
\text { variables (tablero) }\end{array}$ & Acero S 355 J2G3 & $\begin{array}{l}\text { Frame Sections - } \\
\text { Nonprismatic }\end{array}$ \\
\hline $\begin{array}{l}\text { Vigas tubulares D219mm. y E10mm. } \\
\text { (arriostramiento) }\end{array}$ & Acero S 355 J2G3 & Frame Sections - Pipe \\
\hline $\begin{array}{l}\text { Placa de espesor 20 mm. } \\
\text { (arriostramiento) }\end{array}$ & Acero S 355 J2G3 & $\begin{array}{l}\text { Area Sections - Thin } \\
\text { Shell }\end{array}$ \\
\hline Losa de espesor 250 mm. (tablero) & HA-30/B/20/llb & $\begin{array}{l}\text { Area Sections - Thin } \\
\text { Shell }\end{array}$ \\
\hline Péndolas de 45 mm. de diámetro. & Acero Y 1860 S7 & Cable Sections \\
\hline Péndolas de 55 mm. de diámetro. & Acero Y 1860 S7 & Cable Sections \\
\hline
\end{tabular}

\subsubsection{Viga en doble $\mathrm{T}$ de sección variable del tablero}

La definición de la viga en doble "T" del tablero con canto y espesores de las alas y alma variables (Figs. 16 y 17 ) se ha definido con el elemento tipo viga no prismática "Frame Sections - Nonprismatic". 


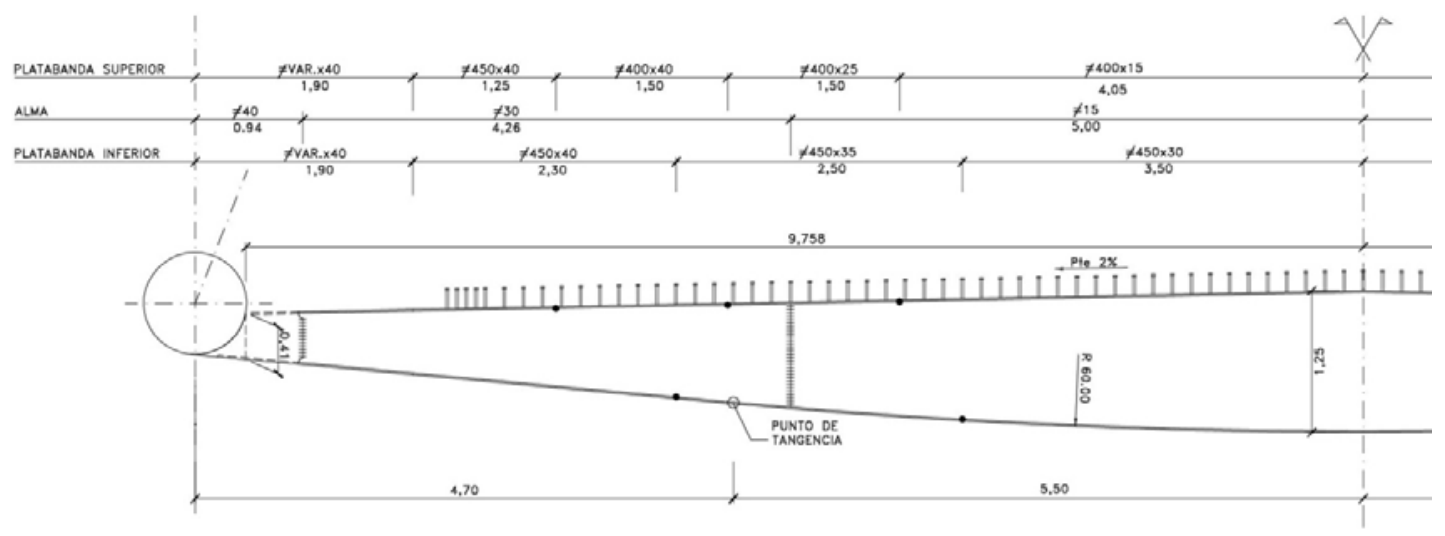

Fig. 16: Detalle del alzado de las vigas transversales del tablero

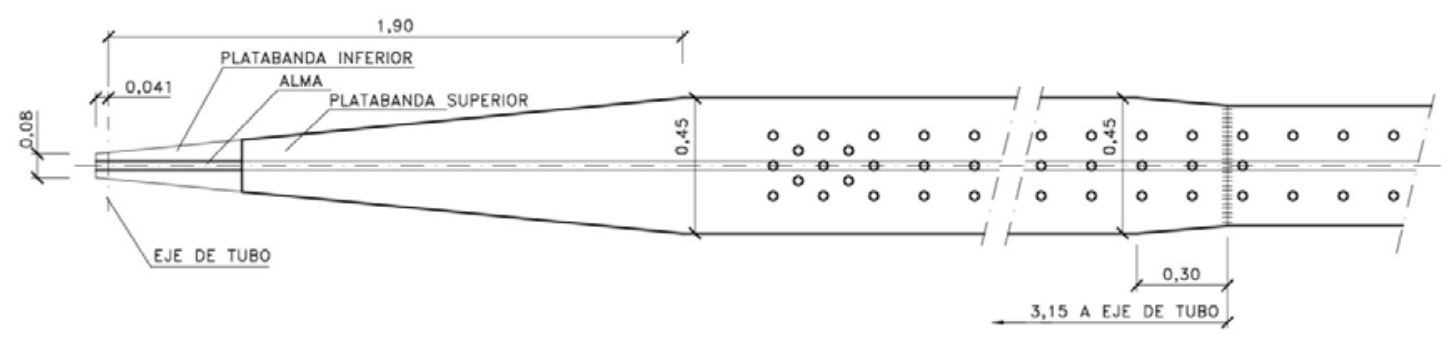

Fig. 17: Detalle en planta de las vigas transversales del tablero

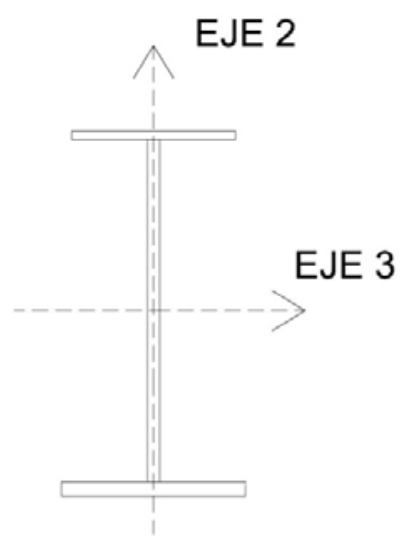

Fig. 18: Detalle sección transversal. Ejes locales 
Para definir una viga no prismática en SAP2000 se estudia las variaciones de las propiedades geométricas. Estas propiedades están caracterizadas por los momentos de inercia de los ejes 2 y 3 (Fig. 18) que son interpolados de forma lineal, parabólica o cúbica según sea la variación a lo largo de la viga (Tabla 2).

Tabla 2: Tipo de interpolación de las propiedades geométrica a lo largo de la viga

\begin{tabular}{|l|c|c|}
\hline Descripción & $\begin{array}{c}\text { Variación } \\
\text { I33 }\end{array}$ & $\begin{array}{c}\text { Variación } \\
\text { I22 }\end{array}$ \\
\hline Variación del canto y anchura de las alas & Cúbica & Cúbica \\
\hline Variación del espesor del alma y anchura de las alas & Parabólica & Cúbica \\
\hline Variación anchura de las alas y del canto de la viga & Cúbica & Cúbica \\
\hline Variación del espesor de las alas y del canto de la viga & Cúbica & Lineal \\
\hline Variación del espesor del alma y del canto de la viga & Parabólica & Cúbica \\
\hline Variación del canto de la viga & Parabólica & Lineal \\
\hline
\end{tabular}

La modelización en SAP2000 de una viga no prismática se realiza de la siguiente forma:

1. Se define las secciones características en la viga (Tabla 3). Se han definido un total de 37 secciones: 18 a cada lado del eje de simetría de V1 a V18 y una en el eje de simetría V19.

2. Se determina la variación de las propiedades geométricas entre las secciones definidas (Tabla 4). 
Tabla 3: Definición de las secciones características en la viga transversal del tablero

\begin{tabular}{|c|c|c|c|c|c|c|c|}
\hline \multirow{2}{*}{$\begin{array}{c}\text { Distancia } \\
\text { desde el } \\
\text { borde }(m)\end{array}$} & \multirow{2}{*}{$\begin{array}{l}\text { Denominación } \\
\text { de la sección }\end{array}$} & \multicolumn{2}{|c|}{ Ala superior } & \multirow{2}{*}{$\begin{array}{c}\text { Alma } \\
\begin{array}{c}\text { Espesor } \\
(\mathrm{m})\end{array}\end{array}$} & \multicolumn{2}{|c|}{ Ala inferior } & \multirow{2}{*}{$\begin{array}{l}\text { Canto } \\
\text { total }(m)\end{array}$} \\
\hline & & $\begin{array}{l}\text { Anchura } \\
(\mathrm{m})\end{array}$ & $\begin{array}{c}\text { Espesor } \\
(\mathrm{m})\end{array}$ & & $\begin{array}{c}\text { Anchura } \\
\text { (m) }\end{array}$ & $\begin{array}{c}\text { Espesor } \\
(\mathrm{m})\end{array}$ & \\
\hline 0,000 & V1 & 0,088 & 0,040 & 0,040 & 0,088 & 0,040 & 0,365 \\
\hline 0,940 & V2 & 0,267 & 0,040 & 0,040 & 0,267 & 0,040 & 0,466 \\
\hline 0,965 & V3 & 0,272 & 0,040 & 0,030 & 0,272 & 0,040 & 0,469 \\
\hline 1,900 & V4 & 0,450 & 0,040 & 0,030 & 0,450 & 0,040 & 0,574 \\
\hline 2,850 & V5 & 0,450 & 0,040 & 0,030 & 0,450 & 0,040 & 0,680 \\
\hline 3,150 & V6 & 0,400 & 0,040 & 0,030 & 0,450 & 0,040 & 0,714 \\
\hline 4,200 & V7 & 0,400 & 0,040 & 0,030 & 0,450 & 0,040 & 0,831 \\
\hline 4,225 & V8 & 0,400 & 0,040 & 0,030 & 0,450 & 0,035 & 0,834 \\
\hline 4,650 & V9 & 0,400 & 0,040 & 0,030 & 0,450 & 0,035 & 0,882 \\
\hline 4,725 & V10 & 0,400 & 0,025 & 0,030 & 0,450 & 0,035 & 0,890 \\
\hline 5,200 & V11 & 0,400 & 0,025 & 0,030 & 0,450 & 0,035 & 0,941 \\
\hline 5,238 & V12 & 0,400 & 0,025 & 0,015 & 0,450 & 0,035 & 0,945 \\
\hline 6,150 & V13 & 0,400 & 0,025 & 0,015 & 0,450 & 0,035 & 1,032 \\
\hline 6,200 & V14 & 0,400 & 0,015 & 0,015 & 0,450 & 0,035 & 1,037 \\
\hline 6,700 & V15 & 0,400 & 0,015 & 0,015 & 0,450 & 0,035 & 1,078 \\
\hline 6,725 & V16 & 0,400 & 0,015 & 0,015 & 0,450 & 0,030 & 1,080 \\
\hline 7,700 & V17 & 0,400 & 0,015 & 0,015 & 0,450 & 0,030 & 1,148 \\
\hline 8,700 & V18 & 0,400 & 0,015 & 0,015 & 0,450 & 0,030 & 1,201 \\
\hline 10,200 & V19 & 0,400 & 0,015 & 0,015 & 0,450 & 0,030 & 1,250 \\
\hline 11,700 & V18 & 0,400 & 0,015 & 0,015 & 0,450 & 0,030 & 1,201 \\
\hline 12,700 & V17 & 0,400 & 0,015 & 0,015 & 0,450 & 0,030 & 1,148 \\
\hline 13,675 & V16 & 0,400 & 0,015 & 0,015 & 0,450 & 0,030 & 1,080 \\
\hline 13,700 & V15 & 0,400 & 0,015 & 0,015 & 0,450 & 0,035 & 1,078 \\
\hline 14,200 & V14 & 0,400 & 0,015 & 0,015 & 0,450 & 0,035 & 1,037 \\
\hline 14,250 & V13 & 0,400 & 0,025 & 0,015 & 0,450 & 0,035 & 1,032 \\
\hline 15,162 & V12 & 0,400 & 0,025 & 0,015 & 0,450 & 0,035 & 0,945 \\
\hline 15,200 & V11 & 0,400 & 0,025 & 0,030 & 0,450 & 0,035 & 0,941 \\
\hline 15,675 & V10 & 0,400 & 0,025 & 0,030 & 0,450 & 0,035 & 0,890 \\
\hline 15,750 & V9 & 0,400 & 0,040 & 0,030 & 0,450 & 0,035 & 0,882 \\
\hline 16,175 & V8 & 0,400 & 0,040 & 0,030 & 0,450 & 0,035 & 0,834 \\
\hline 16,200 & V7 & 0,400 & 0,040 & 0,030 & 0,450 & 0,040 & 0,831 \\
\hline 17,250 & V6 & 0,400 & 0,040 & 0,030 & 0,450 & 0,040 & 0,714 \\
\hline 17,550 & V5 & 0,450 & 0,040 & 0,030 & 0,450 & 0,040 & 0,680 \\
\hline 18,500 & V4 & 0,450 & 0,040 & 0,030 & 0,450 & 0,040 & 0,574 \\
\hline 19,435 & V3 & 0,272 & 0,040 & 0,030 & 0,272 & 0,040 & 0,469 \\
\hline 19,460 & V2 & 0,267 & 0,040 & 0,040 & 0,267 & 0,040 & 0,466 \\
\hline 20,400 & V1 & 0,088 & 0,040 & 0,040 & 0,088 & 0,040 & 0,365 \\
\hline
\end{tabular}


Tabla 4: Variación de las propiedades geométricas entre las secciones definidas en la viga transversal del tablero

\begin{tabular}{|c|c|c|c|c|c|}
\hline \multicolumn{2}{|c|}{ Sección inicial } & \multicolumn{2}{|c|}{ Sección final } & \multirow{2}{*}{ Variación I33 } & \multirow{2}{*}{ Variación I22 } \\
\hline Distancia (m) & Denominación & Distancia (m) & Denominación & & \\
\hline 0,000 & V1 & 0,940 & V2 & Cúbica & Cúbica \\
\hline 0,940 & V2 & 0,965 & V3 & Parabólica & Cúbica \\
\hline 0,965 & V3 & 1,900 & V4 & Cúbica & Cúbica \\
\hline 1,900 & V4 & 2,850 & V5 & Parabólica & Lineal \\
\hline 2,850 & V5 & 3,150 & V6 & Cúbica & Cúbica \\
\hline 3,150 & V6 & 4,200 & V7 & Parabólica & Lineal \\
\hline 4,200 & V7 & 4,225 & V8 & Cúbica & Lineal \\
\hline 4,225 & V8 & 4,650 & V9 & Parabólica & Lineal \\
\hline 4,650 & V9 & 4,725 & V10 & Cúbica & Lineal \\
\hline 4,725 & V10 & 5,200 & V11 & Parabólica & Lineal \\
\hline 5,200 & V11 & 5,238 & V12 & Parabólica & Cúbica \\
\hline 5,238 & V12 & 6,150 & V13 & Parabólica & Lineal \\
\hline 6,150 & V13 & 6,200 & V14 & Cúbica & Lineal \\
\hline 6,200 & V14 & 6,700 & V15 & Parabólica & Lineal \\
\hline 6,700 & V15 & 6,725 & V16 & Cúbica & Lineal \\
\hline 6,725 & V16 & 7,700 & V17 & Parabólica & Lineal \\
\hline 7,700 & V17 & 8,700 & V18 & Parabólica & Lineal \\
\hline 8,700 & V18 & 10,200 & V19 & Parabólica & Lineal \\
\hline 10,200 & V19 & 11,700 & V18 & Parabólica & Lineal \\
\hline 11,700 & V18 & 12,700 & V17 & Parabólica & Lineal \\
\hline 12,700 & V17 & 13,675 & V16 & Parabólica & Lineal \\
\hline 13,675 & V16 & 13,700 & V15 & Cúbica & Lineal \\
\hline 13,700 & V15 & 14,200 & V14 & Parabólica & Lineal \\
\hline 14,200 & V14 & 14,250 & V13 & Cúbica & Lineal \\
\hline 14,250 & V13 & 15,162 & V12 & Parabólica & Lineal \\
\hline 15,162 & V12 & 15,200 & V11 & Parabólica & Cúbica \\
\hline 15,200 & V11 & 15,675 & V10 & Parabólica & Lineal \\
\hline 15,675 & V10 & 15,750 & V9 & Cúbica & Lineal \\
\hline 15,750 & V9 & 16,175 & V8 & Parabólica & Lineal \\
\hline 16,175 & V8 & 16,200 & V7 & Cúbica & Lineal \\
\hline 16,200 & V7 & 17,250 & V6 & Parabólica & Lineal \\
\hline 17,250 & V6 & 17,550 & V5 & Cúbica & Cúbica \\
\hline 17,550 & V5 & 18,500 & V4 & Parabólica & Lineal \\
\hline 18,500 & V4 & 19,435 & V3 & Cúbica & Cúbica \\
\hline 19,435 & V3 & 19,460 & V2 & Parabólica & Cúbica \\
\hline 19,460 & V2 & 20,400 & V1 & Cúbica & Cúbica \\
\hline
\end{tabular}




\subsection{Condiciones de contorno}

El viaducto está simplemente apoyado en sus extremos. Se diseñaron en cada uno de los extremos cuatro apoyos: dos en los bordes y los otros dos a 3,5 m. del borde (fig. 19).

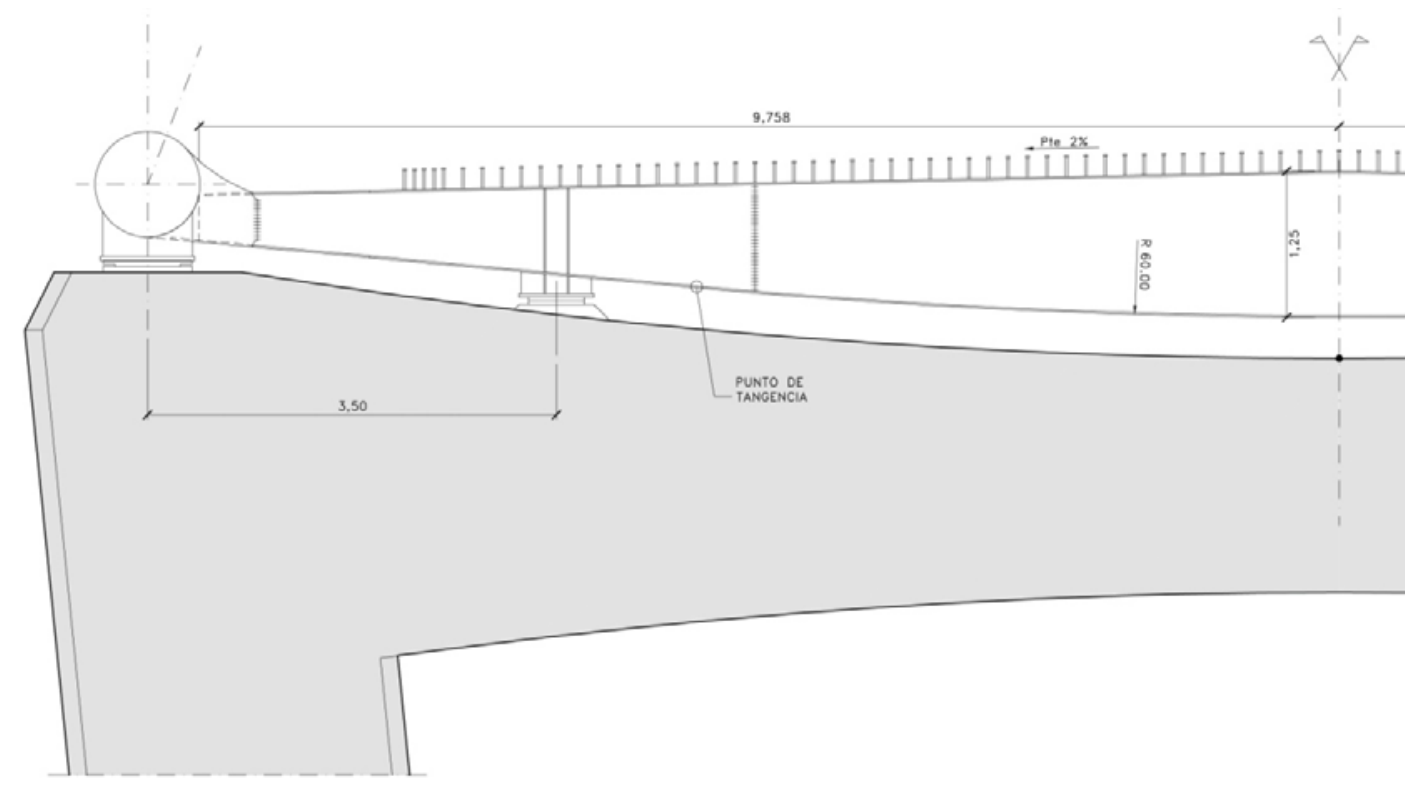

Fig. 19: Localización de los Aparatos de Apoyo

Las condiciones de contorno consideradas en el modelo (Fig. 20) son las siguientes:

- Extremo 1 ( $X=-130)$ : Los cuatro apoyos se han considerado como apoyos fijos. Se impide totalmente la traslación de la sección del apoyo y se permite el giro. Restricciones: u1, u2 y u3.

- Extremo $2(X=0)$ : Los cuatro apoyos se han considerado como apoyos móviles. Se permite el movimiento longitudinal y el giro de la sección del apoyo. Restricciones: u2 y u3. 
Fig. 20: Localización de los Aparatos de Apoyo en Modelo definido en SAP2000

\subsection{Análisis estático no lineal}

El análisis no lineal efectuado tiene por objeto obtener la posición deformada de las péndolas y tener en cuenta los efectos de grandes deformaciones producidos en las mismas. A partir del estado de rigidez obtenido al final del proceso iterativo del análisis estático no lineal se realizará el análisis modal.

SAP2000 tiene implementados varios métodos para cálculo no lineal, como el método de Newton-Raphson, Newton-Raphson modificado, Line-Search, así como varias opciones de estabilización de tales algoritmos y la combinación de los mismos. Todo problema de elementos finitos ha de cumplir una serie de ecuaciones que satisfagan simultáneamente la siguiente igualdad:

$$
[K]\{u\}=\left\{F^{a}\right\}
$$

Cuando la matriz de rigidez $[\mathrm{K}]$ depende de valores desconocidos de los grados de libertad (caso de grandes deformaciones en cables), la anterior ecuación es 
no lineal y debe ser resuelta mediante alguno de los métodos iterativos indicados en el párrafo anterior.

$$
\begin{gathered}
\left.\left[K_{i}^{T}\right], \Delta \Delta u_{i}\right\}=\left\{F^{a}\right\}-\left\{F_{i}^{n r}\right\} \\
\left\{u_{i+1}\right\}=\left\{u_{i}\right\}+\left\{\Delta u_{i}\right\}
\end{gathered}
$$

Donde $\left[K_{i}^{\top}\right]$ es la matriz de rigidez tangente, $\left\{u_{i}\right\}$ el vector de desplazamientos, $\left\{F_{a}\right\}$ el vector de cargas aplicadas y $\left\{F_{i}{ }^{n r}\right\}$ es el vector de fuerzas calculado a partir de las tensiones de los elementos. El subíndice i representa la iteración de equilibrio.

En este trabajo se ha empleado para el análisis estático no lineal el algoritmo por defecto que trae implementado SAP2000 ver. 14.1.0 en el que principalmente combina técnicas iterativas de resolución como Newton-Raphson y Line-Search.

\subsubsection{Acciones}

El estado de acciones considerado para el análisis estático no lineal es el correspondiente a la aplicación de las cargas permanentes (peso propio y cargas muertas) sin ningún coeficiente parcial de seguridad. Las acciones se han definido con los mismos parámetros utilizados en el Proyecto de Construcción [6].

\section{Peso propio}

La densidad de los materiales aplicada en el modelo es la siguiente:

- Acero S $355 \mathrm{~J} 2 \mathrm{G} 3: \mathrm{Y}=7.850 \mathrm{Kg} / \mathrm{m}^{3}$

- Acero Y $1860 \mathrm{~S} 7: \quad \mathrm{V}=7.850 \mathrm{Kg} / \mathrm{m}^{3}$

- HA-30/B/20/llb: $\quad Y=2.550 \mathrm{Kg} / \mathrm{m}^{3}$

\section{Carga muerta}

Pavimento aplicado sobre el tablero: $\quad 1,5 \times 0,06 \times 2,3 \times 9,81=2,03 \mathrm{KN} / \mathrm{m}^{2}$

Barrera metálica: $\quad 0,15 \times 9,81=1,47 \mathrm{KN} / \mathrm{m}$

\section{Tesado previo en las péndolas}

- 10 tn en las pendolas 18 y 22 .

- 24 tn en las pendolas 1 y 46.

- 21 tn en las pendolas 2 y 45 . 
En el modelo se han incorporado estas tensiones previas como deformaciones preexistentes en las péndolas. Las deformaciones incorporadas son las siguientes:

Péndolas 18 y 22: $u 1=L x \sigma / E=27,52 \times 61.618 / 1,95 E 8=0,008696 \mathrm{~m}$.

Péndolas 1 y 46: $\quad u 1=L x \sigma / E=11,97 \times 147.884 / 1,95 E 8=0,009081 \mathrm{~m}$.

Péndolas 2 y 45: $\quad u 1=L x \sigma / E=14,59 \times 86.622 / 1,95 E 8=0,006479 \mathrm{~m}$.

\subsubsection{Resultados}

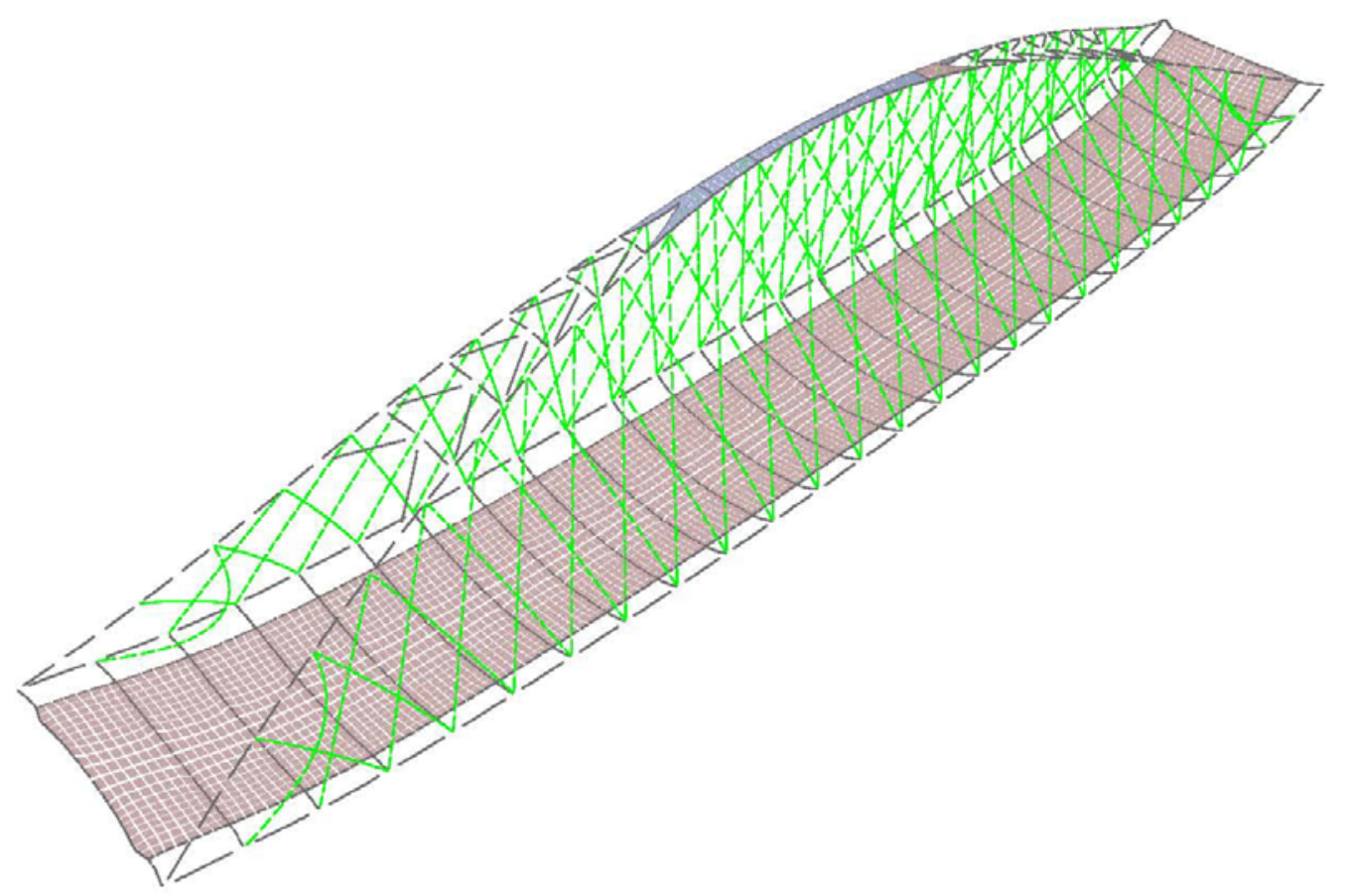

Fig. 21: Deformada del cálculo no lineal. Factor de Escala 30.

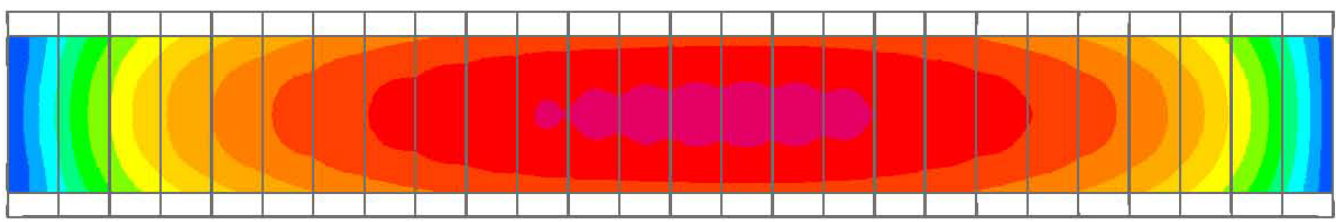

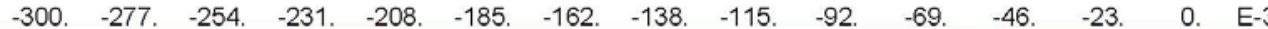

Fig. 22: Deformada (Uz) del tablero del cálculo no lineal. 


\subsection{Análisis modal}

El análisis modal se ha efectuado a partir del estado de rigidez obtenido del análisis estático no lineal descrito en el apartado anterior.

Se han obtenido las soluciones al problema clásico de valores propios presentado por la ecuación del movimiento de un sistema de múltiples grados de libertad:

$$
\left([K]-\omega^{2}[M]\right) \cdot\{\phi\}=0
$$

Se han obtenido los diez primeros modos de vibración. Estos modos de vibración se definirán como modos objetivo a identificar en el proceso de Optimización de Localización de Sensores (OSP).

Tabla 5: Comparación de frecuencias $(\mathrm{Hz})$

\begin{tabular}{|l|l|l|l|}
\hline $\begin{array}{l}\text { Modo de } \\
\text { vibración }\end{array}$ & Dirección & Descripción & Frecuencia \\
\hline $1^{\circ}$ modo & Flexión del tablero (Eje Y) & Una onda & 1.345 \\
\hline $2^{\circ}$ modo & Flexión en el arco & - & 1.592 \\
\hline $3^{\circ}$ modo & Flexión del tablero (Eje Y) & Una semionda & 1.596 \\
\hline $4^{\circ}$ modo & Flexión en el arco & - & 1.657 \\
\hline $5^{\circ}$ modo & Flexión del tablero (Eje Y) & Una onda y media & 1.893 \\
\hline $6^{\circ}$ modo & Flexión del tablero (Eje Z) & Una semionda & 1.908 \\
\hline $7^{\circ}$ modo & Flexión del tablero (Eje Y) & Dos ondas & 2.383 \\
\hline $8^{\circ}$ modo & Torsión del tablero & - & 2.600 \\
\hline $9^{\circ}$ modo & Flexión del tablero (Eje Y) & Dos ondas y media & 2.883 \\
\hline $10^{\circ}$ modo & Torsión del tablero & - & 3.172 \\
\hline
\end{tabular}




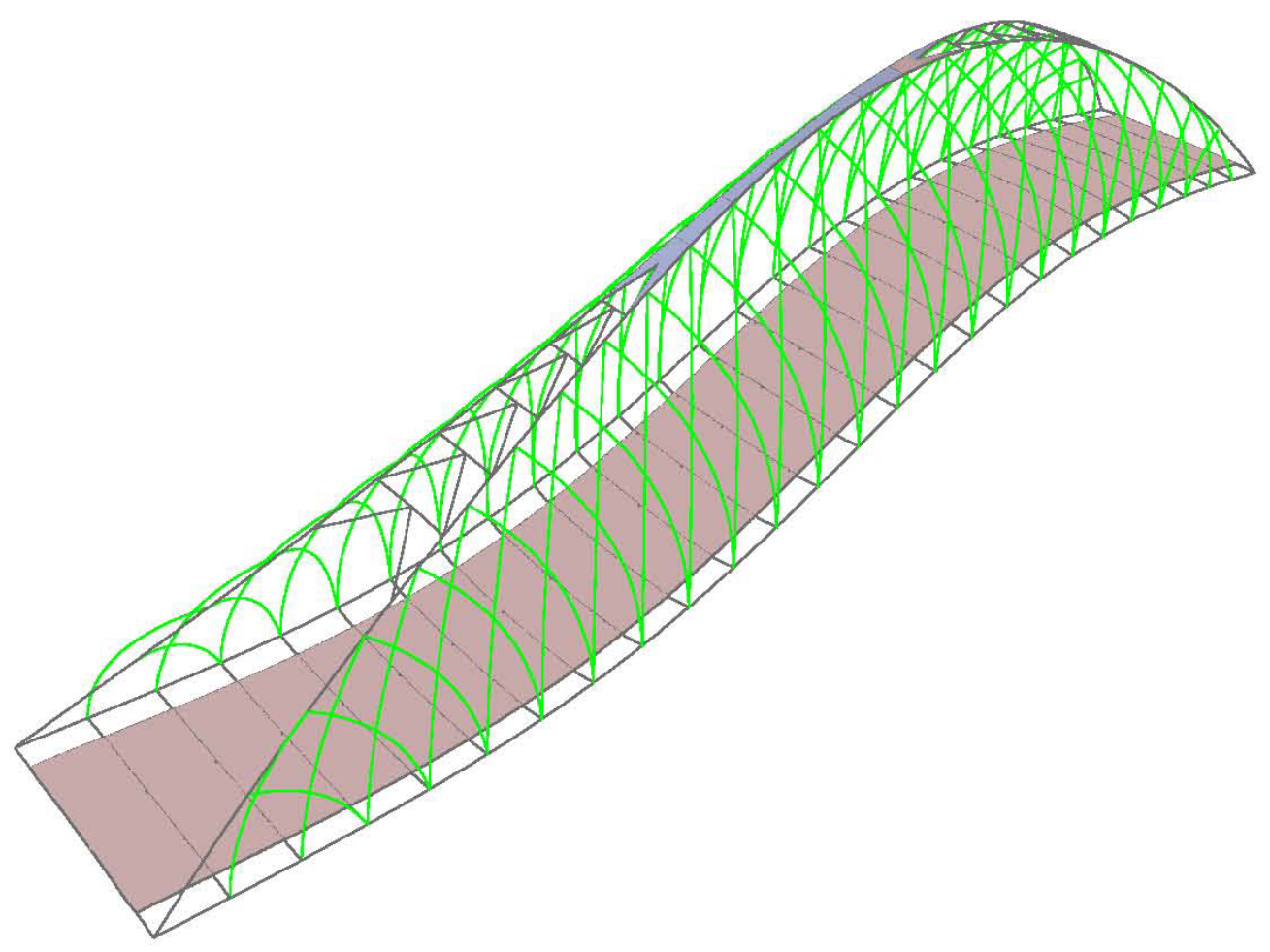

Fig. 23: Primer modo de vibración. Perspectiva 3D

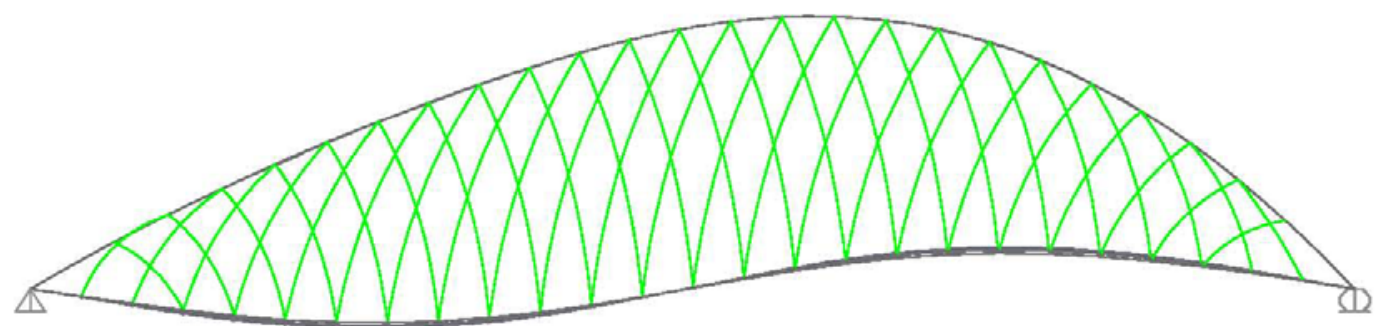

Fig. 24: Primer modo de vibración. Alzado 


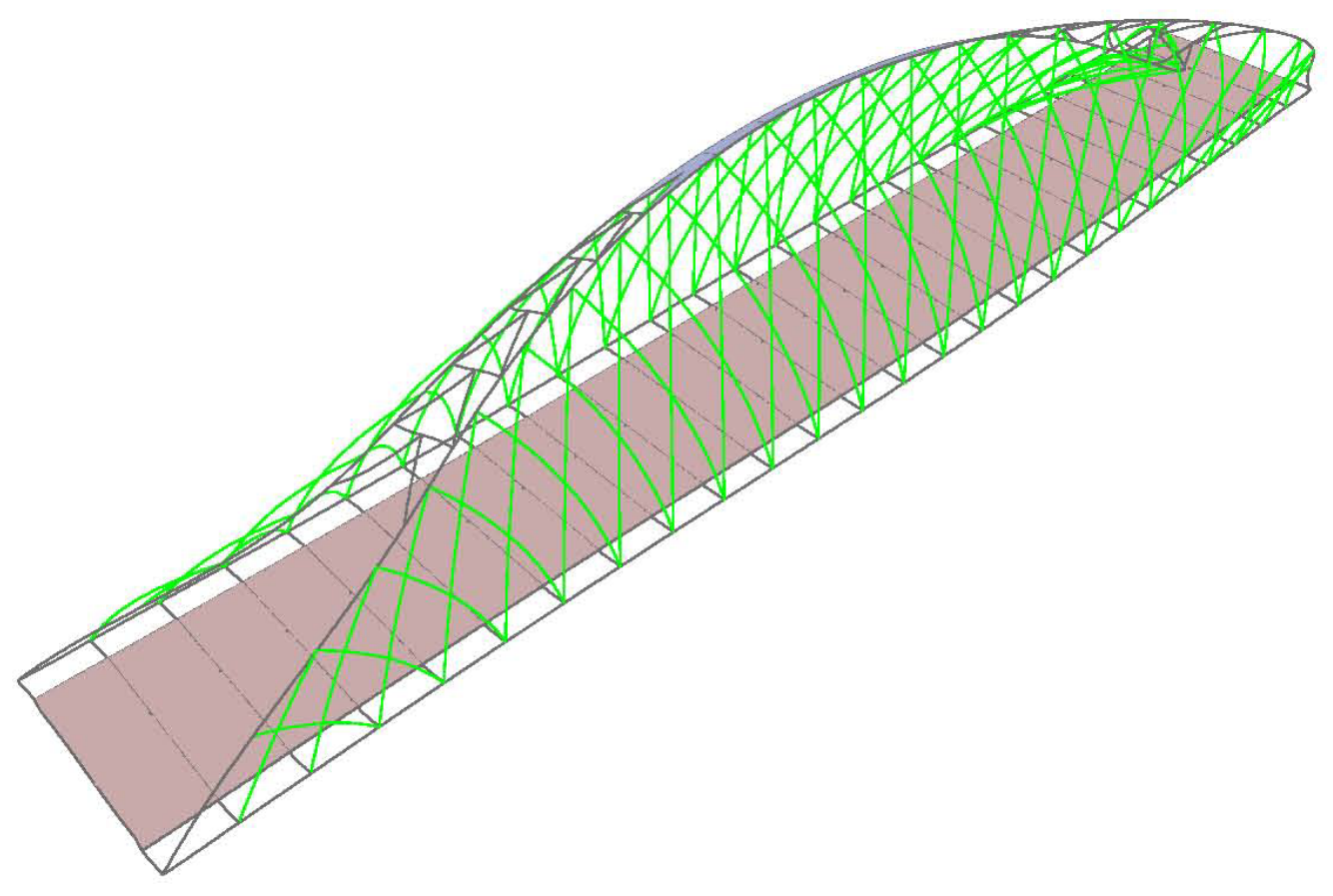

Fig. 25: Segundo modo de vibración. Perspectiva 3D

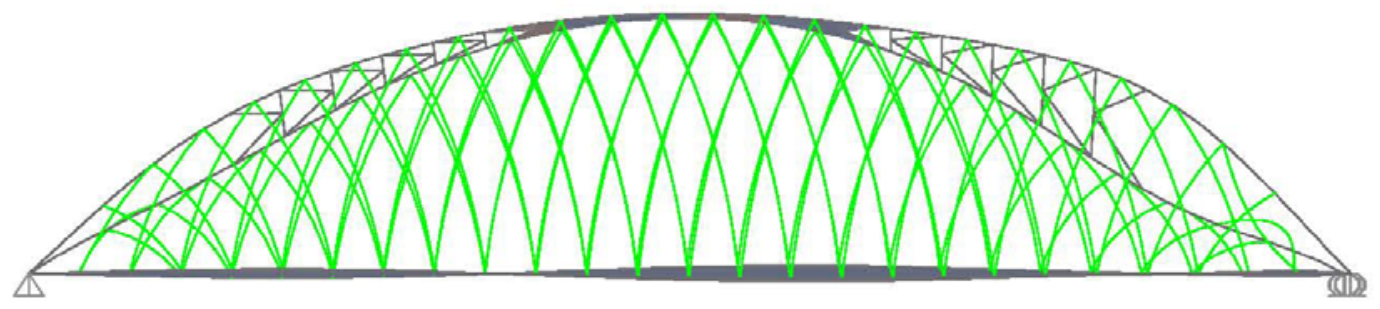

Fig. 26: Segundo modo de vibración. Alzado 


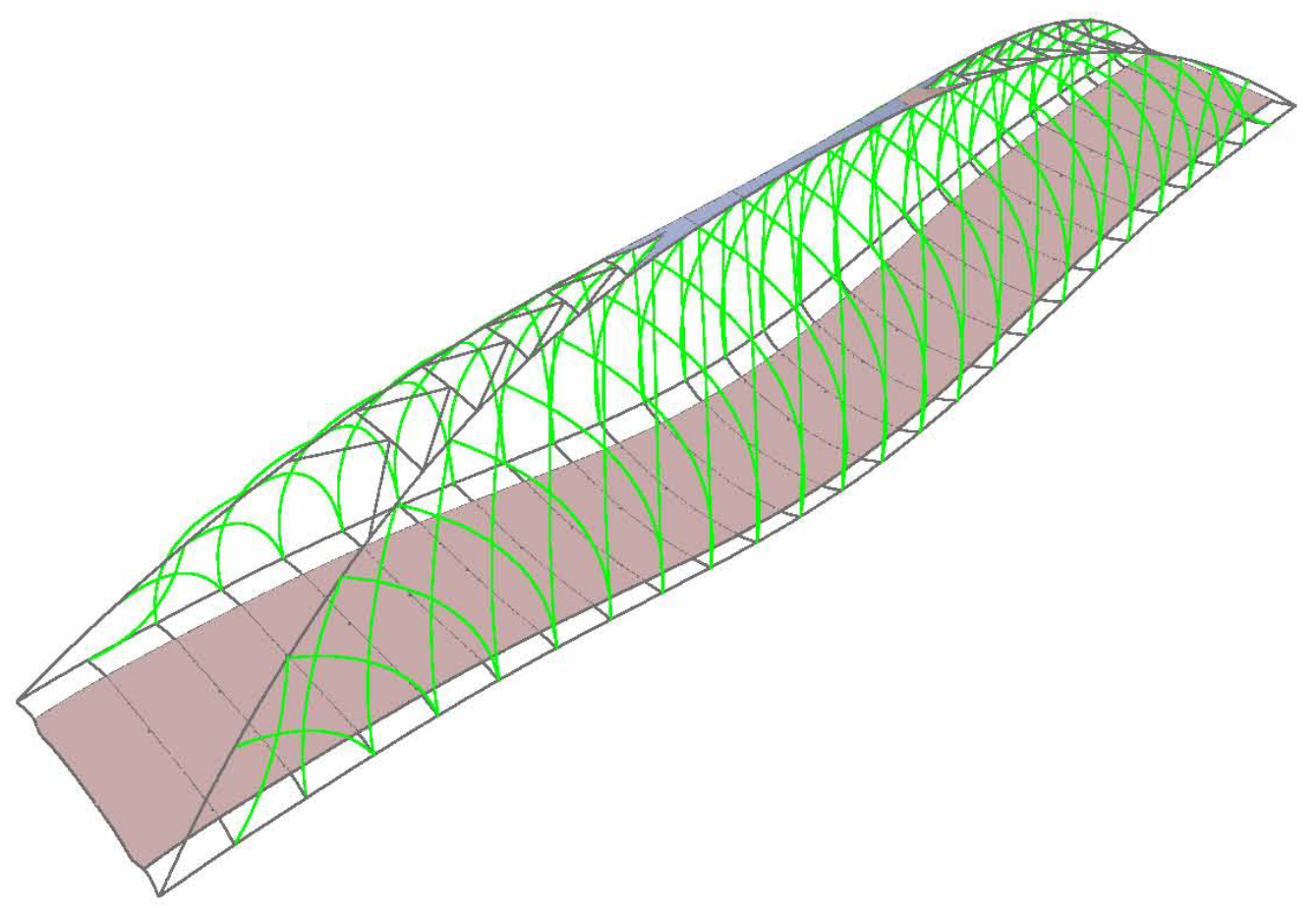

Fig. 27: Tercer modo de vibración. Perspectiva 3D

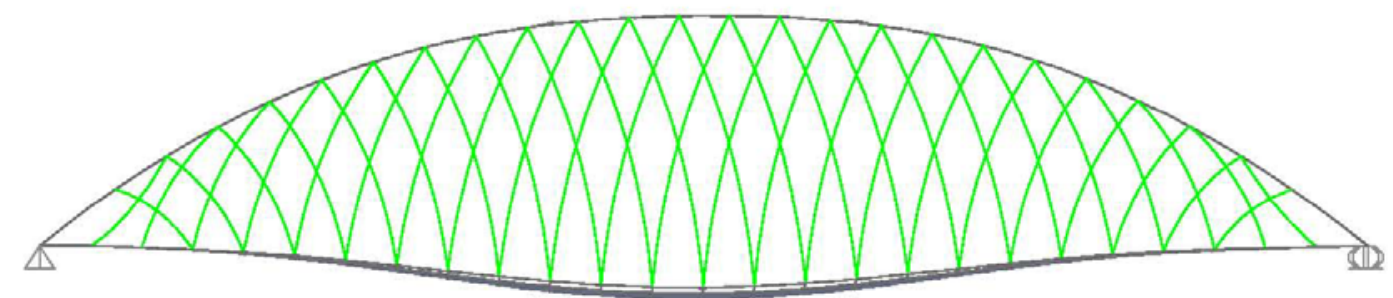

Fig. 28: Tercer modo de vibración. Alzado 


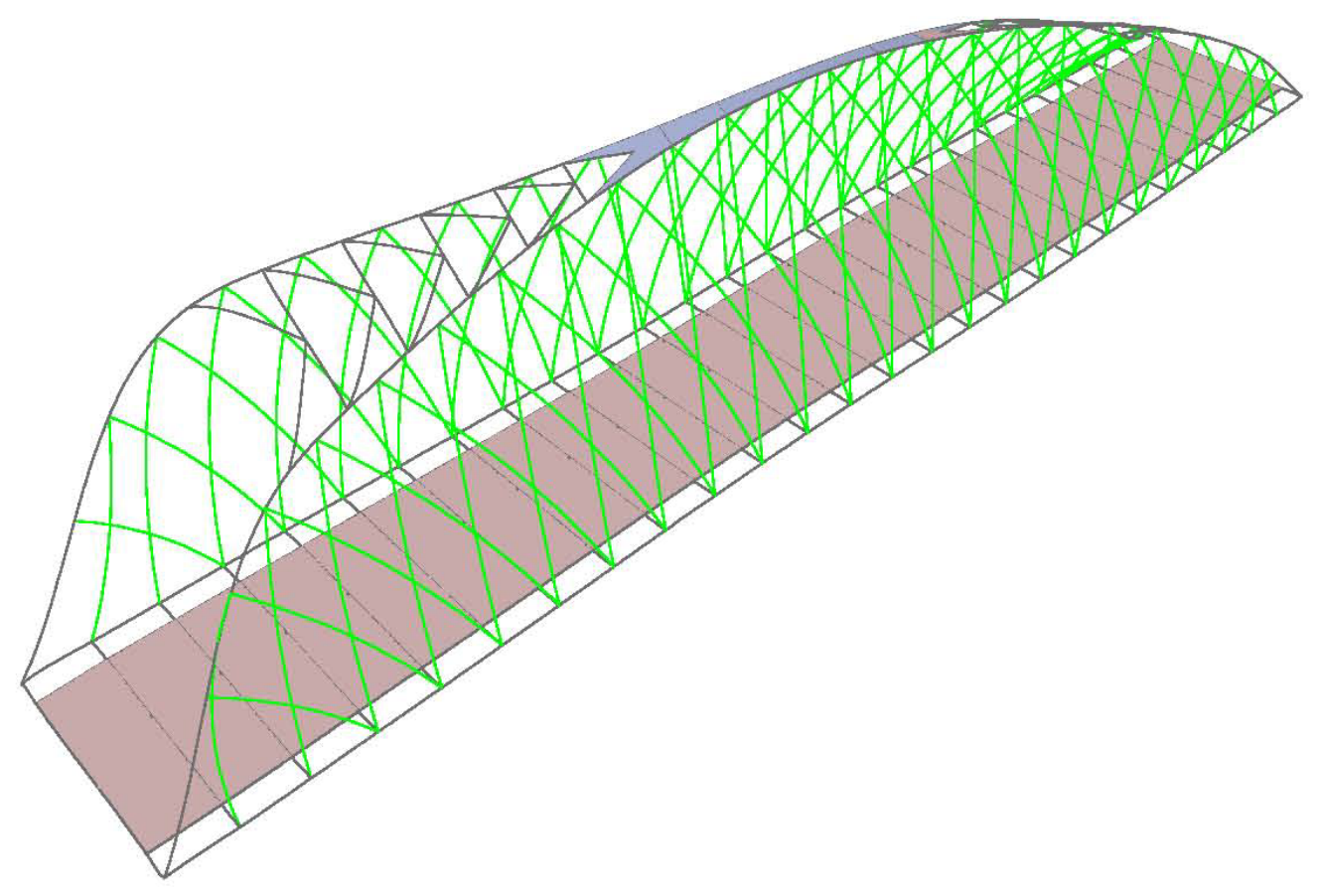

Fig. 29: Cuarto modo de vibración. Perspectiva 3D

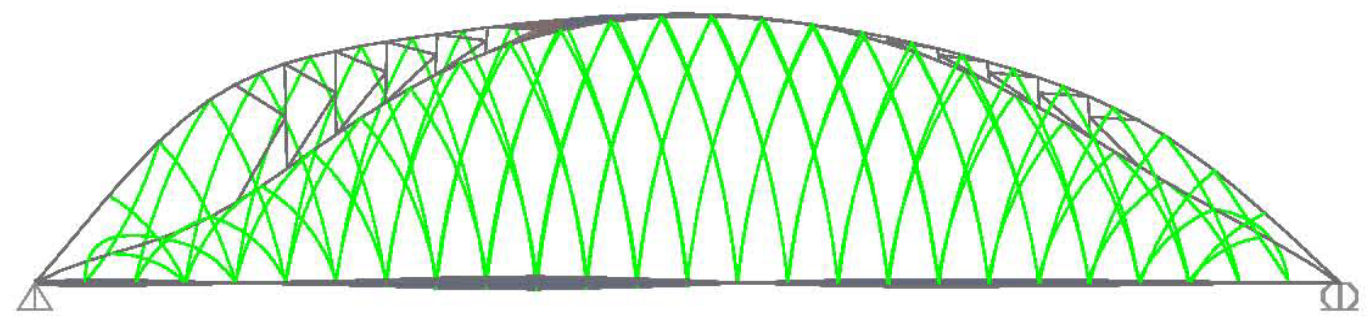

Fig. 30: Cuarto modo de vibración. Alzado 


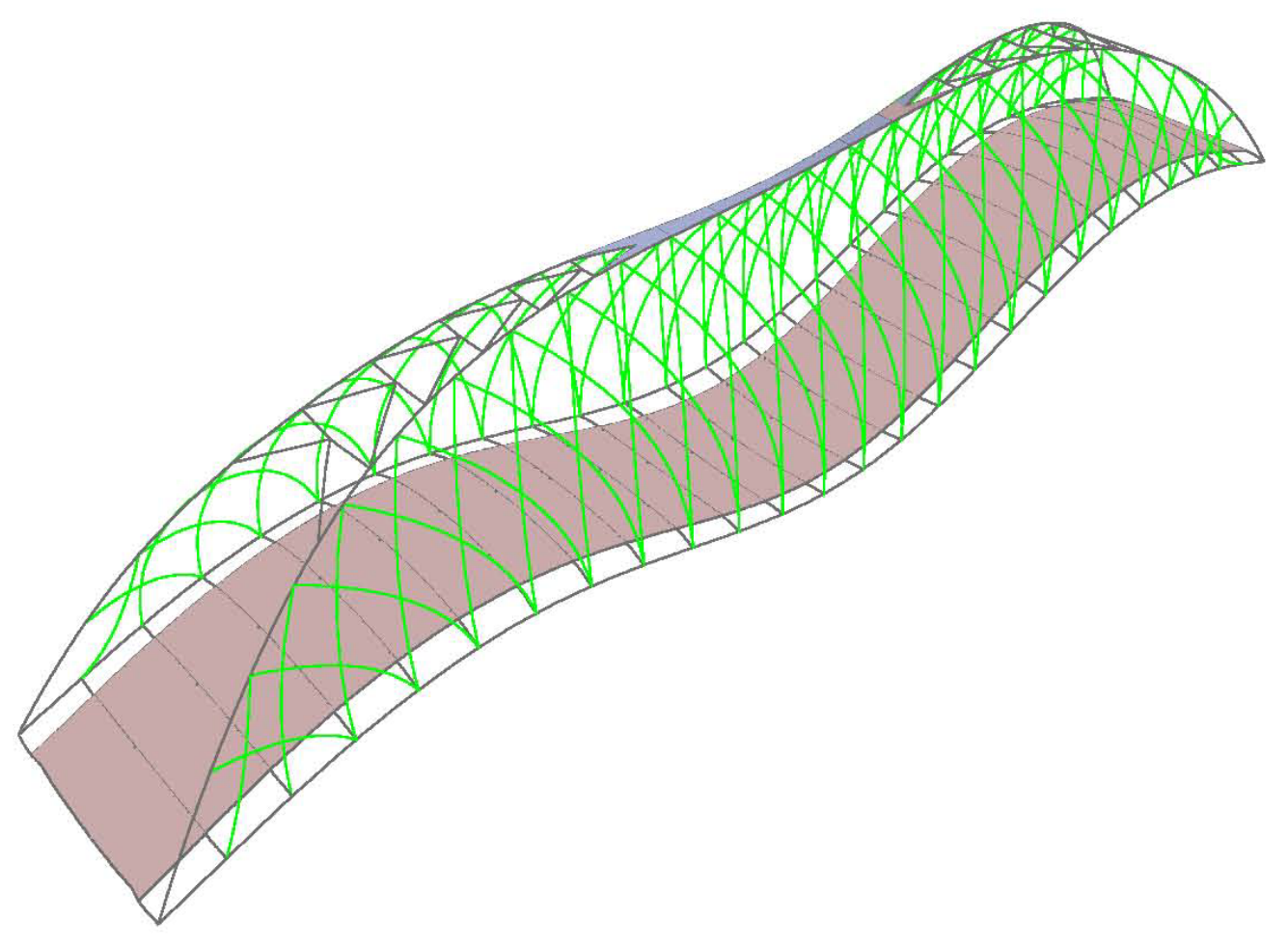

Fig. 31: Quinto modo de vibración. Perspectiva 3D

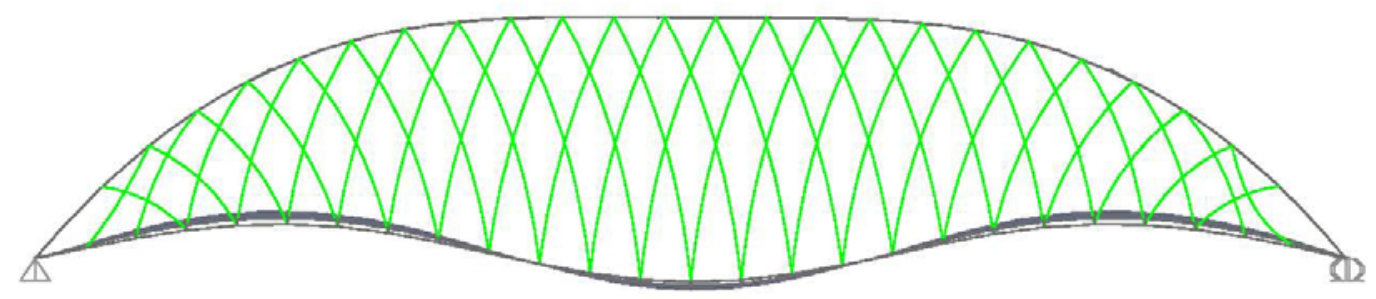

Fig. 32: Quinto modo de vibración. Alzado 


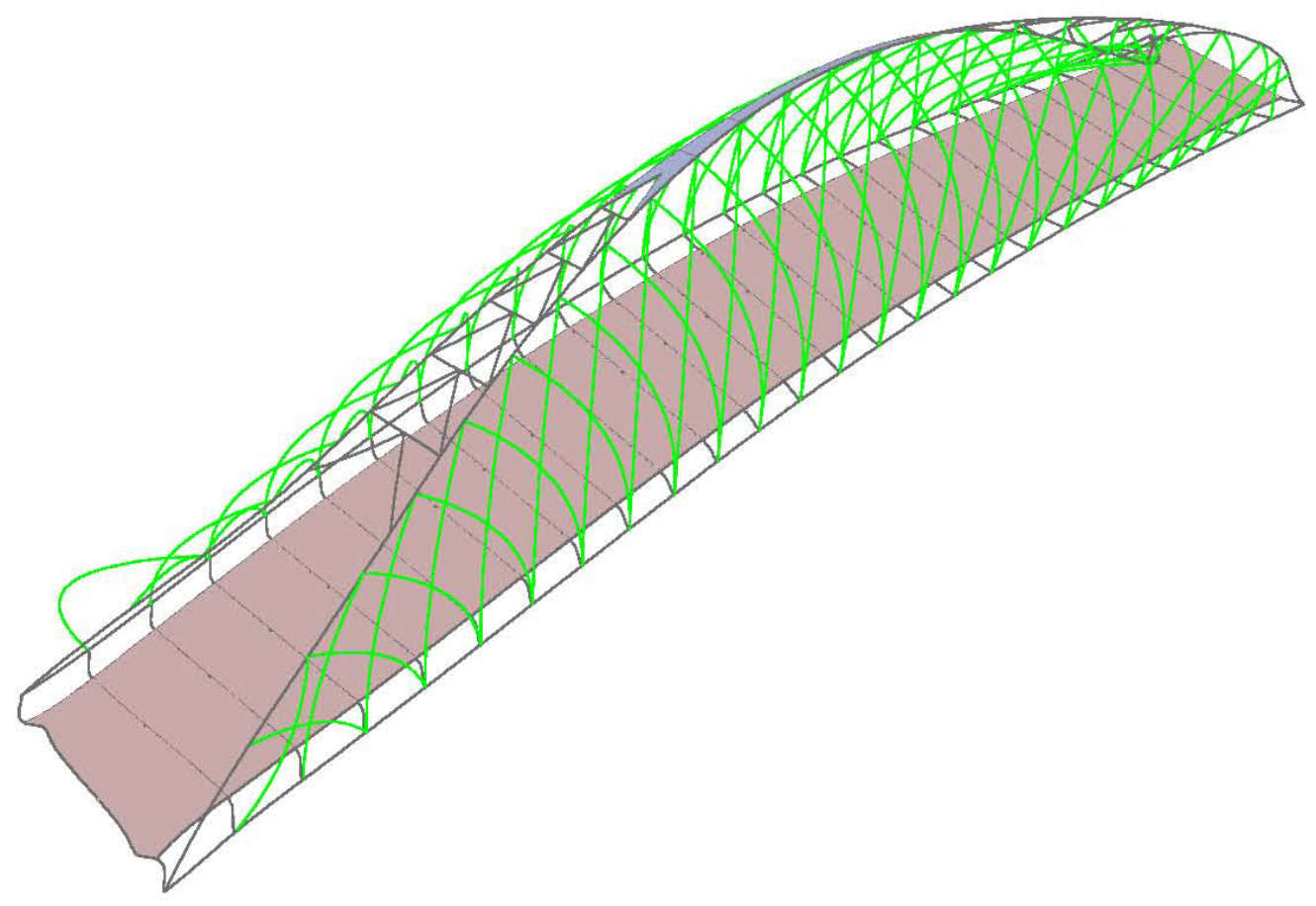

Fig. 33: Sexto modo de vibración. Perspectiva 3D

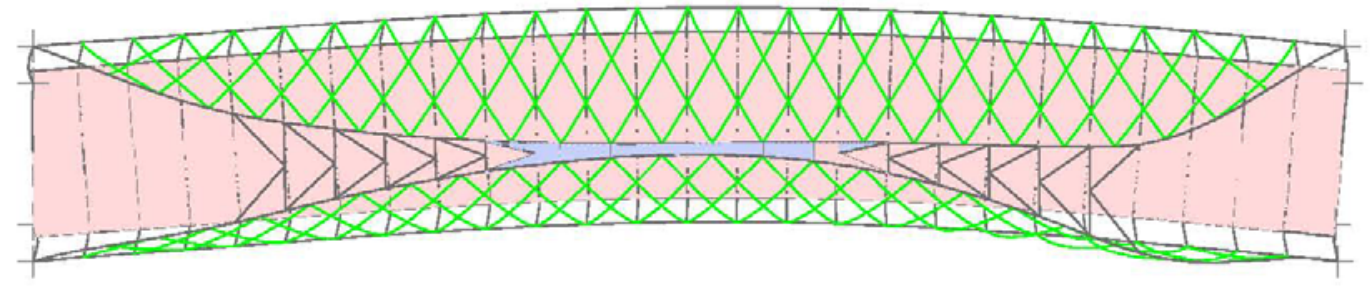

Fig. 34: Sexto modo de vibración. Planta 


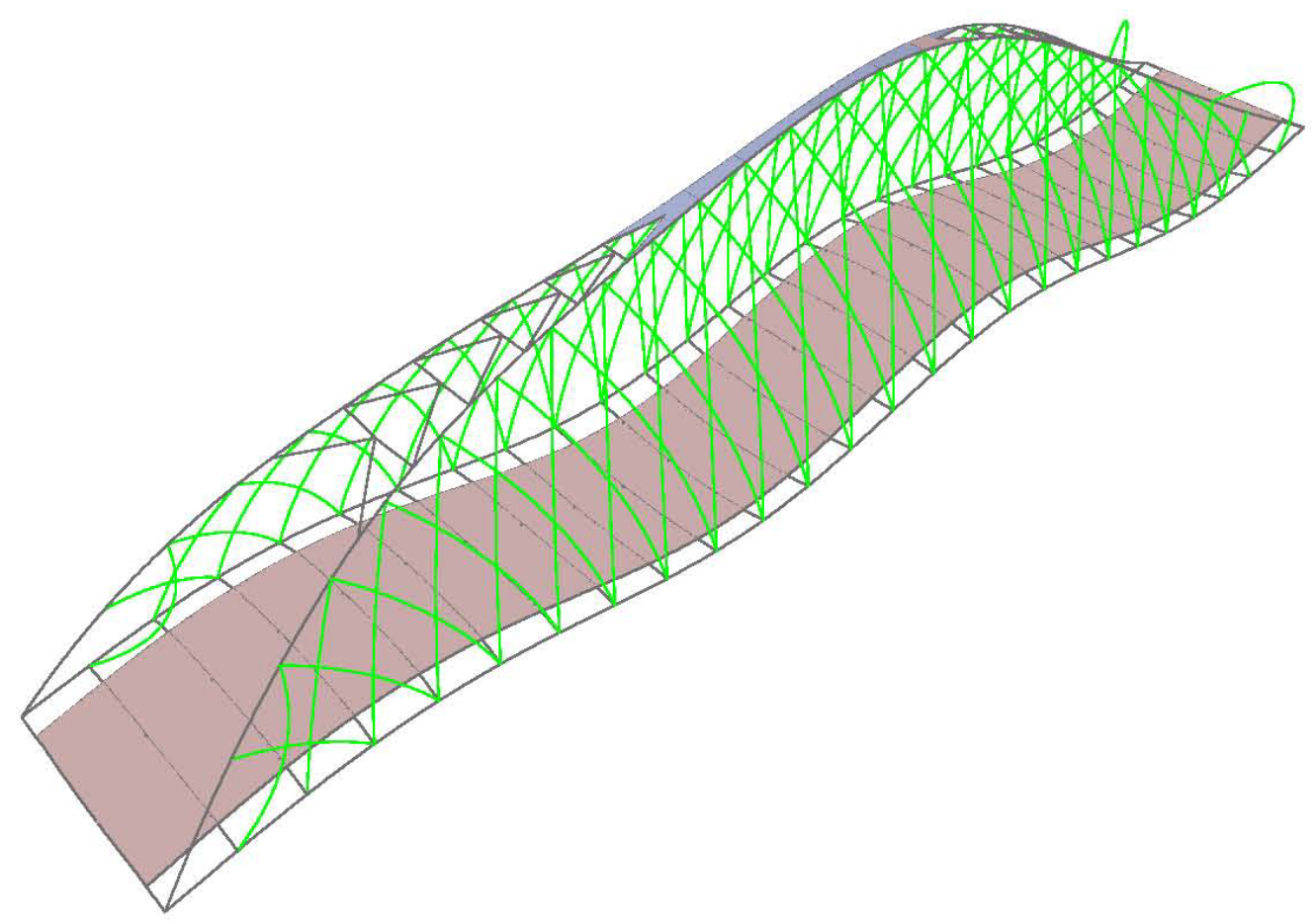

Fig. 35: Séptimo modo de vibración. Perspectiva 3D

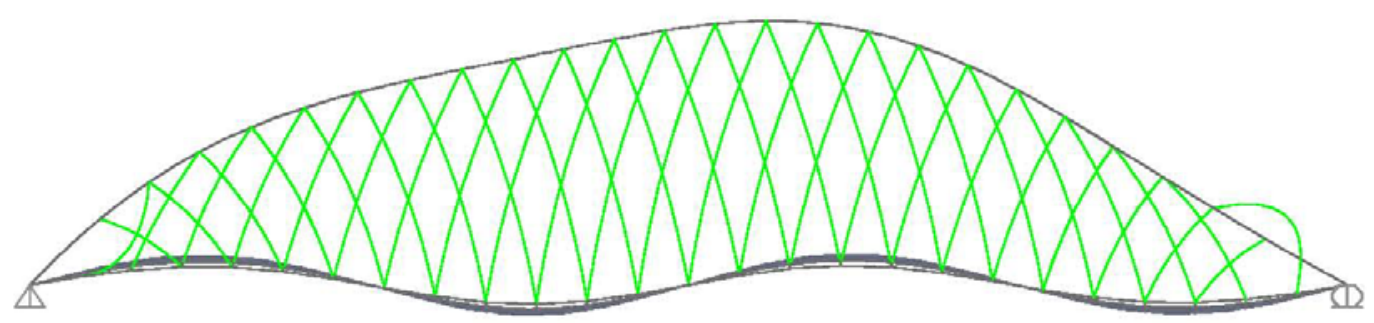

Fig. 36: Séptimo modo de vibración. Alzado 


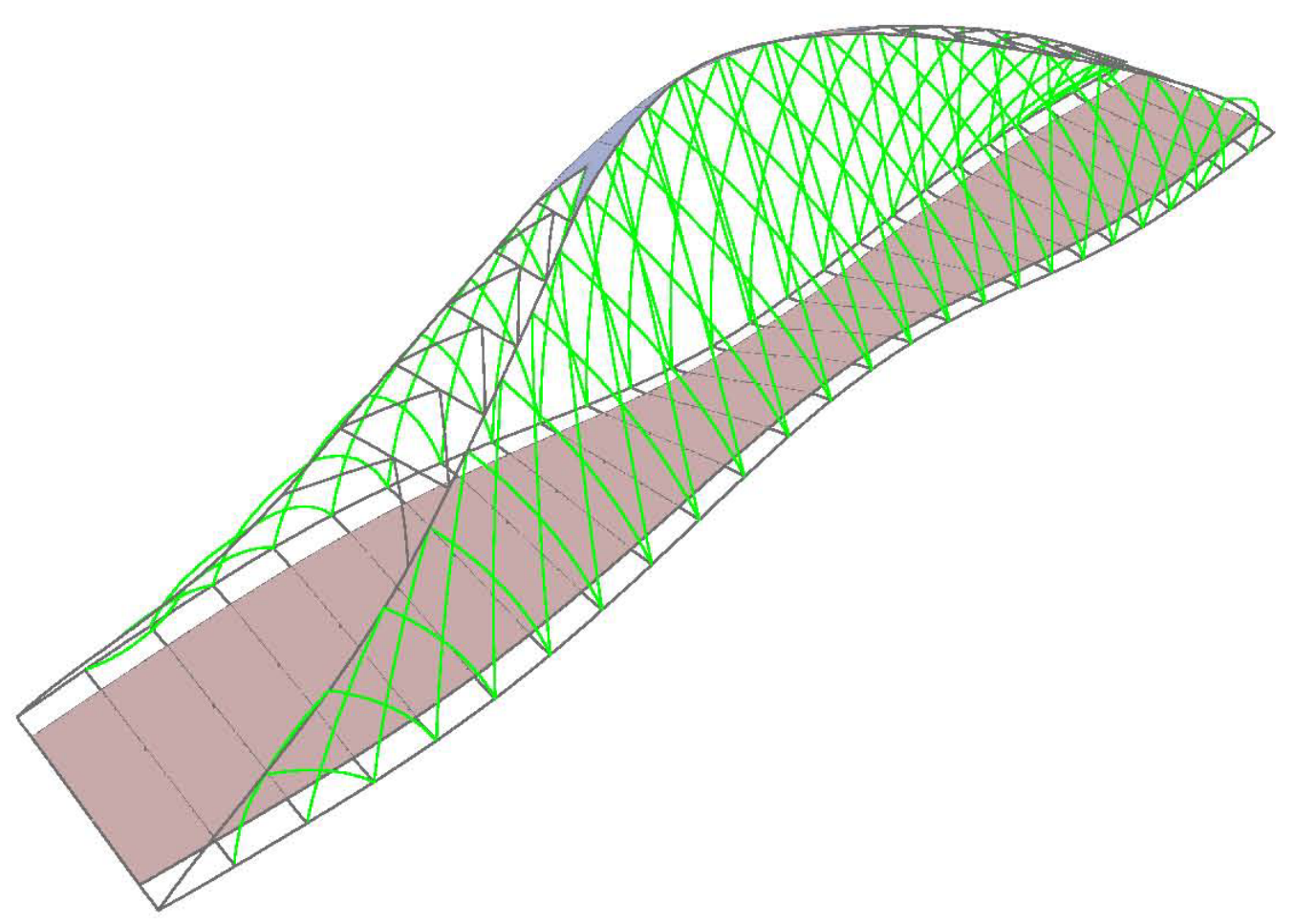

Fig. 37: Octavo modo de vibración. Perspectiva 3D

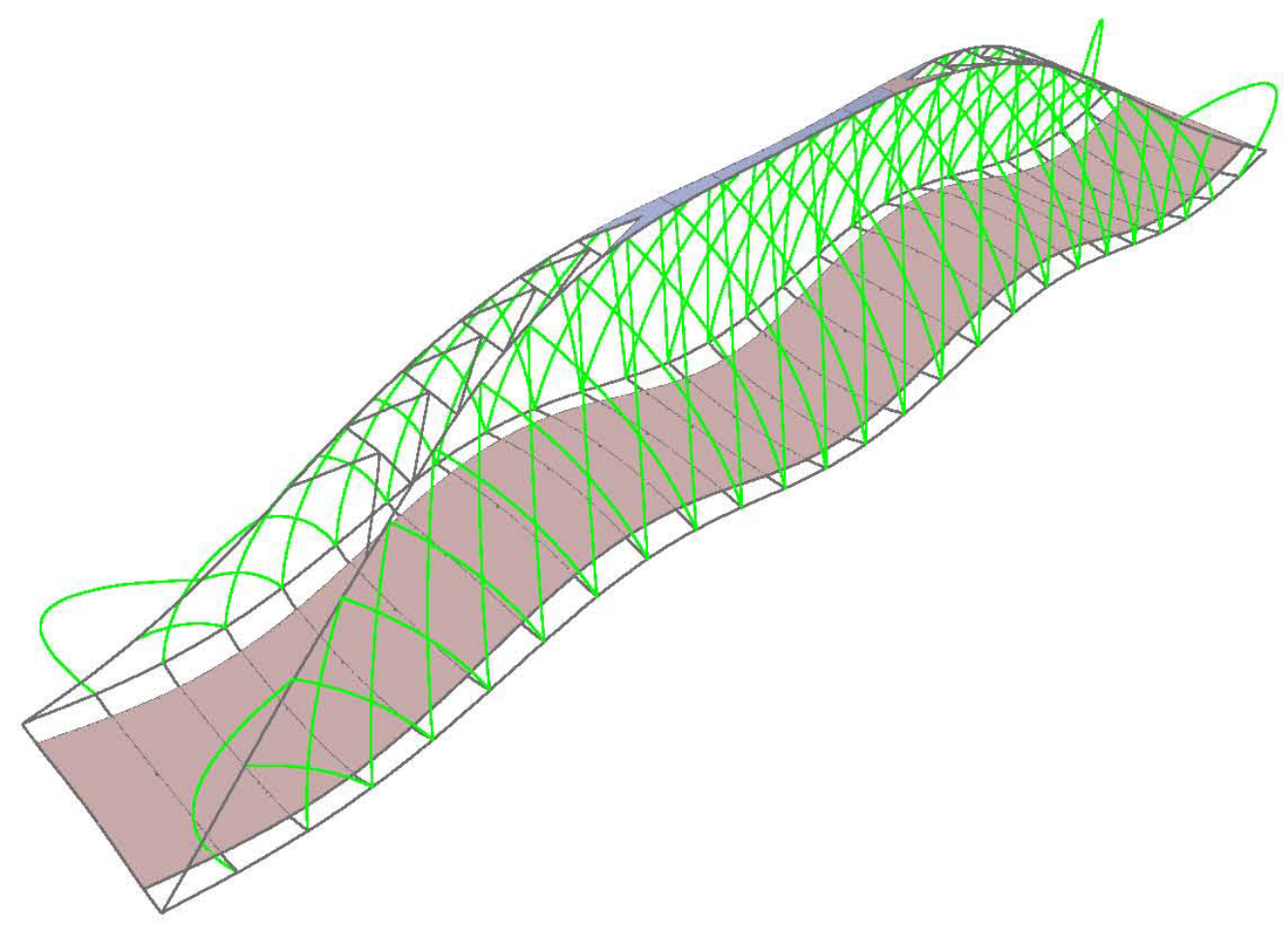

Fig. 38: Noveno modo de vibración. Perspectiva 3D 


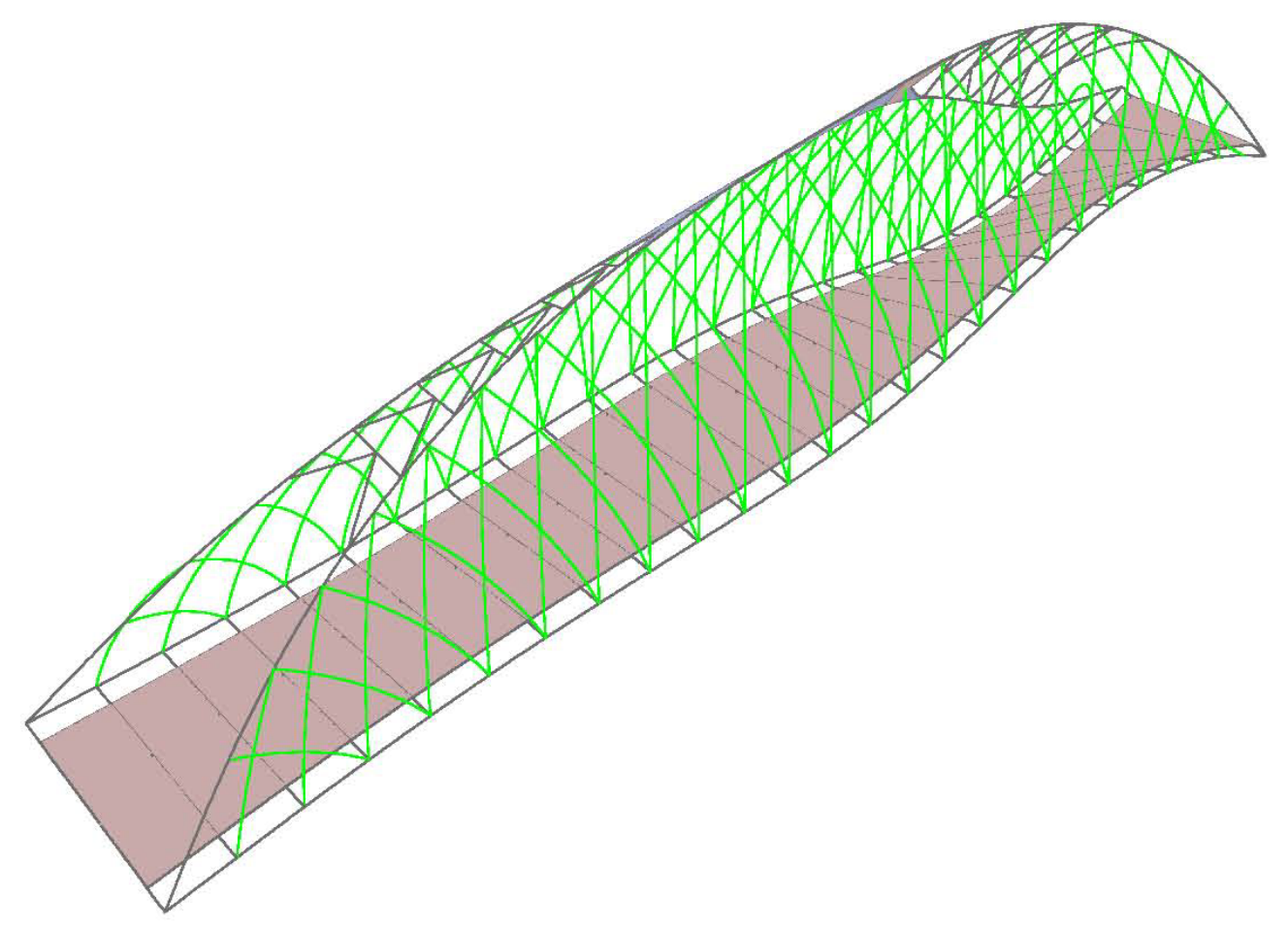

Fig. 39: Décimo modo de vibración. Perspectiva 3D 


\section{METODOLOGÍA DE OPTIMIZACIÓN DE LOCALIZACIÓN DE SENSORES}

\subsection{Procedimiento de trabajo}

El problema de Optimización de Localización de Sensores (OSP) consiste en situar un determinado número de sensores en las posiciones cuyos grados de libertad proporcionen la mayor información posible de la estructura a identificar.

Para llevar a cabo este proceso se implementa una rutina en MATLAB que ejecuta SAP2000 y que contiene el algoritmo de optimización según el método EFI. La rutina lee la matriz modal, de rigidez y de masas obtenidas para que el algoritmo de optimización localice la posición de los sensores en esa estructura.

Esta herramienta desarrollada en MATLAB se va a utilizar para estudiar distintas configuraciones de sensores (5-8-10-12-15 acelerómetros) con el objeto de identificar los diez primeros modos de vibración.

\subsection{Método de Optimización EFI}

El método empleado en este trabajo es el Método EFI (Effective Independence Method - Método de la Independencia Efectiva sin ningún tipo de ponderación). El cual consiste en evaluar el rango de una matriz que llamaremos Matriz de Información de Fisher (FIM).

Para ello, y en primer lugar, se extraen de la matriz modal completa [Ф] las columnas de los $t$ modos de vibración objetivo que se quieren identificar, y las filas de los s grados de libertad candidatos a optimizar, obteniendo la matriz $[\Phi]_{\text {sxt }}$. Con esta matriz se define la matriz FIM:

$$
F I M=\left[A_{0}\right]_{t x t}=[\Phi]_{s \times t}^{t}[\Phi]_{s \times t}
$$

El método consiste en eliminar iterativamente de la matriz FIM las filas de los grados de libertad linealmente dependientes (información redundante), manteniendo los que contribuyen a la independencia lineal de la misma (máxima información). 


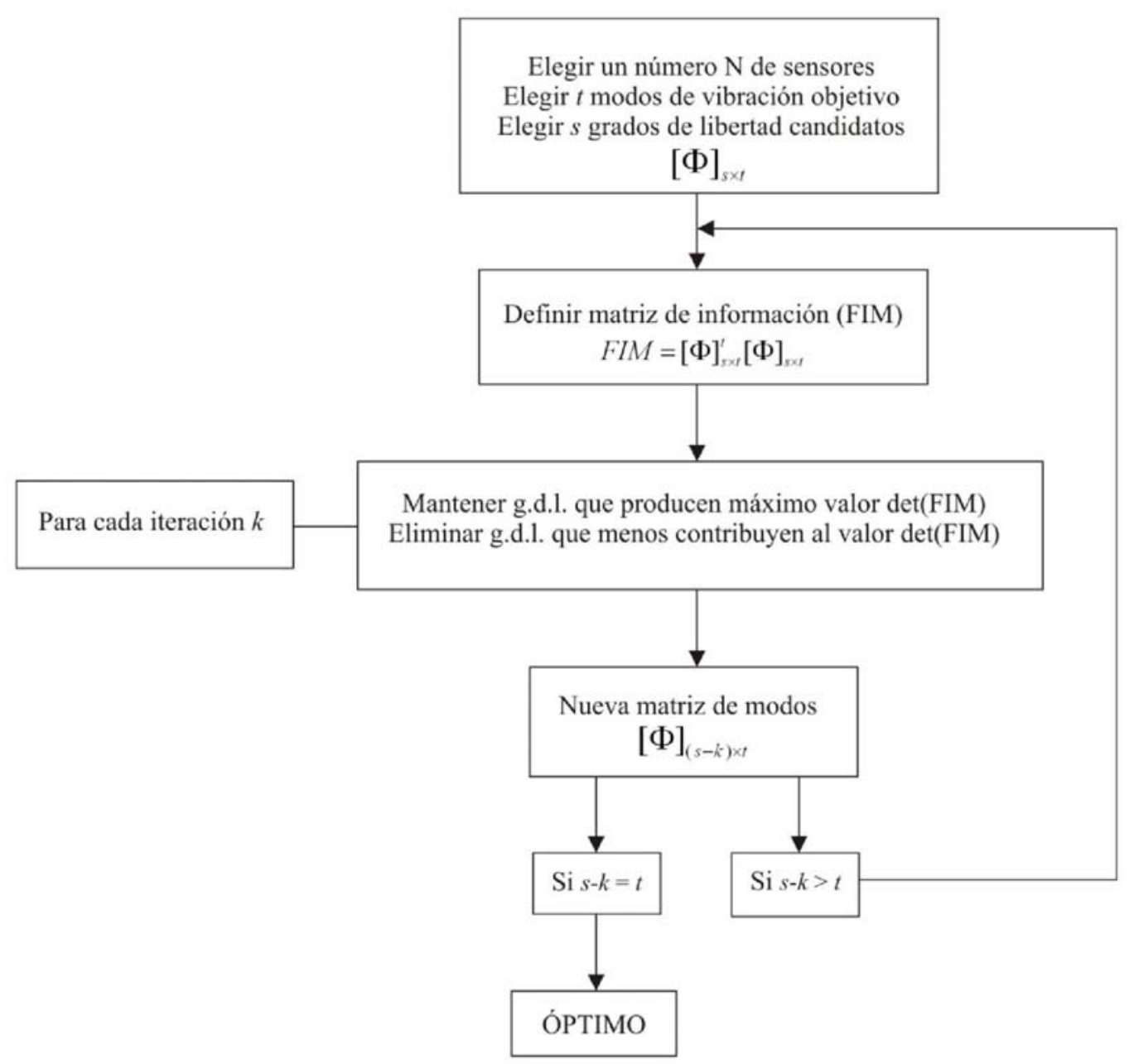

Fig. 40. Diagrama de flujo del algoritmo implementado en MATLA. Vergara [5]

La matriz FIM es una matriz de Gram. El problema de optimización consiste en encontrar el mejor conjunto de grados de libertad activos de una serie de grados de libertad candidatos de tal manera que:

- $\quad$ Si $\operatorname{det}(\mathrm{FIM})$ es máximo $\rightarrow$ Vectores linealmente independientes $\rightarrow$ Máxima información (el algoritmo mantiene esa fila de grados de libertad).

- $\mathrm{Si} \operatorname{det}(\mathrm{FIM})=0 \rightarrow$ Vectores linealmente dependientes $\rightarrow$ Información redundante (el algoritmo elimina la fila que menos contribuye al valor del determinante).

Se han tomado sólo los grados de libertad traslacionales (Ux,Uy,Uz) del tablero como grados de libertad candidatos. En primer lugar, esto es debido a que los acelerómetros disponibles para un posterior trabajo en campo no miden grados de libertad rotacionales. En segundo lugar sólo podemos medir las traslaciones de los 
nodos del tablero dado que no podemos colocar acelerómetros ni en el arco ni en la viga perimetral externa por motivos de acceso.

\subsection{Resultados}

El algoritmo implementado en MATLAB según el método EFI proporciona las localizaciones óptimas para las distintas configuraciones de sensores (5-8-10-12-15 acelerómetros). Los resultados completos se exponen en las tabla 6 y en las figuras $41,42,43,44,45$ y 46.

Los resultados muestran que la optimización de los sensores con el método EFI presenta posiciones muy similares variando el número de sensores a optimizar.

Tabla 6: Localización óptima de sensores según EFI

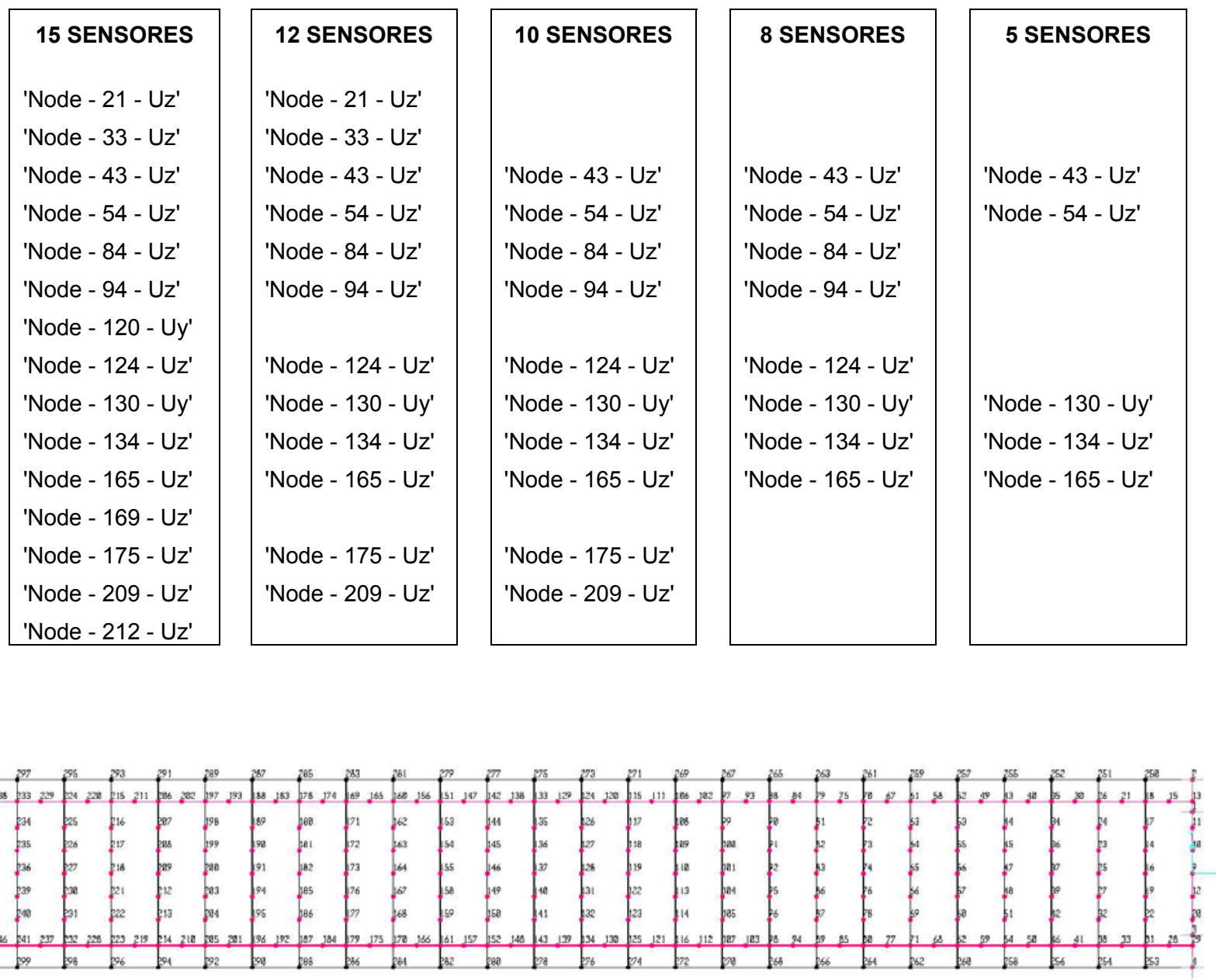

Fig. 41: Puntos candidatos en el tablero para realizar la optimización 


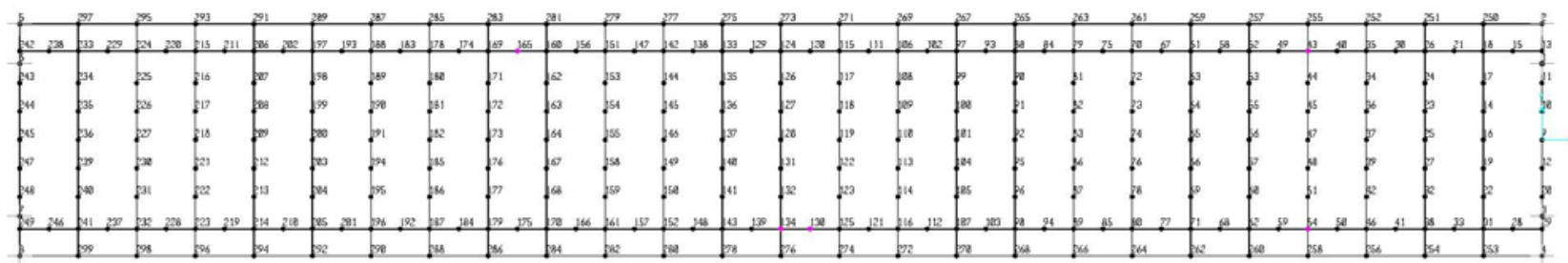

Fig. 42: Optimización de 5 sensores según Método EFI

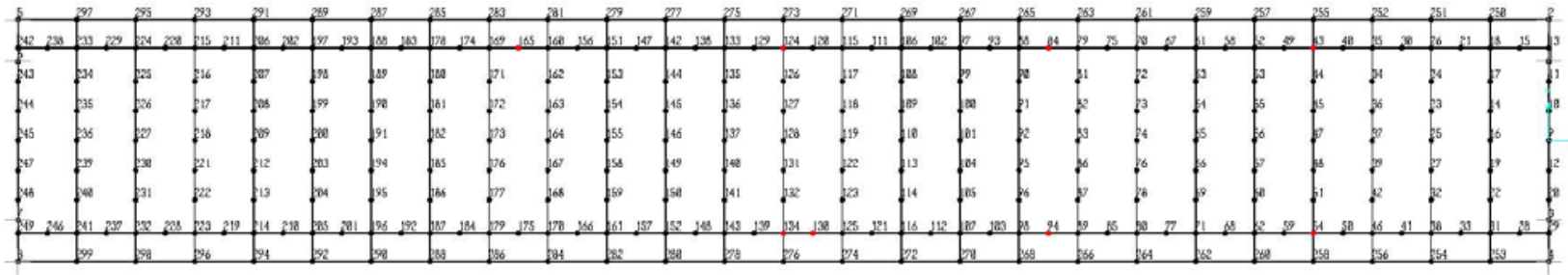

Fig. 43: Optimización de 8 sensores según Método EFI

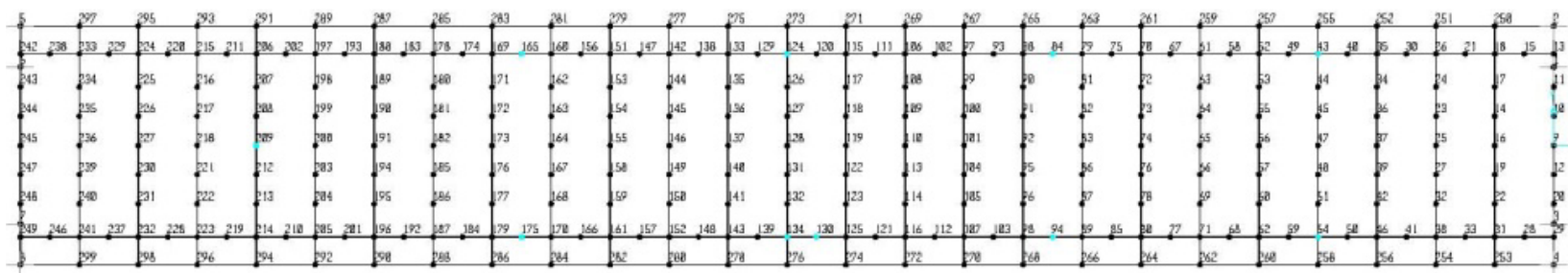

Fig. 44: Optimización de 10 sensores según Método EFI

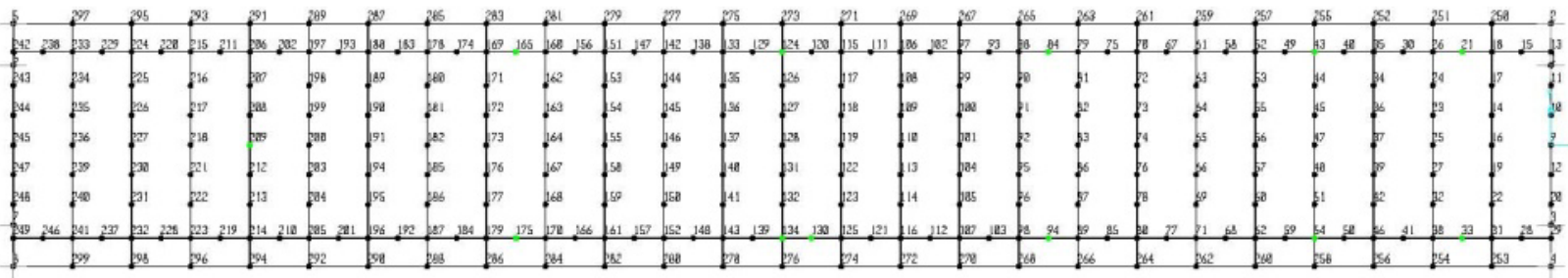

Fig. 45: Optimización de 12 sensores según Método EFI

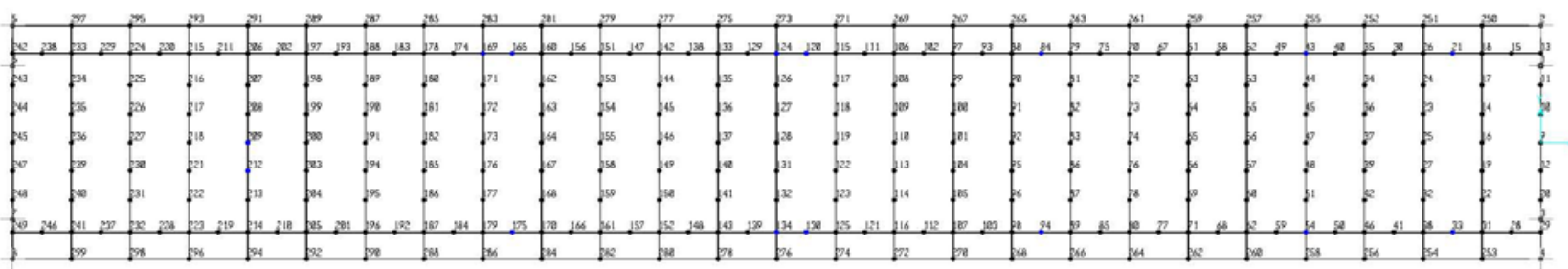

Fig. 46: Optimización de 15 sensores según Método EFI 


\section{CONCLUSIONES Y TRABAJOS FUTUROS}

Se ha presentado una metodología de Optimización de Localización de Sensores (OSP) para identificación estructural del Puente Arco en Palma del Rio mediante Análisis Modal Operacional (OMA).

Se ha aplicado el método EFI para la optimización de la localización de distintas configuraciones de sensores. Se han localizado los grados de libertad que mayor información proporcionaban para identificar los modos objetivo, confirmando la eficacia de esta metodología. Consecuentemente, esto mejorará las tareas de Análisis Modal Operacional, proporcionando una monitorización más eficiente de la estructura: se obtendrán datos más exactos y se empleará el número preciso de acelerómetros, abaratando costes en la adquisición de los mismos y agilizando los trabajos de campo.

Se sugiere la utilización de esta optimización en trabajos experimentales en el Viaducto de Palma del Rio mediante Análisis Modal Operacional y comparar los resultados obtenidos con otro tipo de configuraciones habituales de los sensores, para así constatar de manera práctica la eficacia del método propuesto y plantear posibles mejoras en caso de ser necesario. La monitorización de estructuras suele llevarse a cabo mediante un barrido de acelerómetros que cubren un gran número de posiciones en la estructura a fin de obtener la máxima información posible, a costa de emplear también un gran número de acelerómetros. De ahí la importancia de aplicar este método de optimización, pues se ahorrarán costes en el número de acelerómetros adquiridos y se agilizarán los trabajos de campo.

Se propone comparar los resultados del método de optimización EFI con los obtenidos mediante métodos de optimización bio-inspirados como los algoritmos genéticos para evaluar el rendimiento de ambos. 


\section{BIBLIOGRAFÍA}

[1] Lazarevic, A., Kanapady, R., Kamath, C., Kumar, V. \& Tamma, K. Effective localized regression for damage detection in large complex mechanical structures. KDD-2004 - Proceedings of the Tenth ACM SIGKDD International Conference on Knowledge Discovery and Data Mining 450-459 (2004).

[2] Lazarevic, A. M., Kanapady, R., Tamma, K. K., Kamath, C. \& Kumar, V. Damage prediction in structural mechanics using partitioning approach. Proceedings of SPIE5098, 202-210 (2003).

[3] Li, D.-S. \& Li, H.-N. The state of art of sensor placement methods in structural health monitoring. Proceedings of SPIE - The International Society for Optical Engineering6174 II, (2006).

[4] Millanes F., Ortega M., Carnerero A., Project of two metal arch bridges with tubular elements and network suspension system. Steelbridges: Advanced Solucitions \& Technologies Conference Proceedings. 7th International Conference on Steel Bridges. pp. II-88 a II-96. Published by: ECCSEuropean Convenrtion for Constructiuon SteelWork.

[5] Vergara J.A., Trabajo Fin de Master optimización de localización de sensores para identificación estructural de Torres Eléctricas mediante análisis modal operacional.

[6] Proyecto de Construcción del Nuevo Puente sobre el Rio Guadalquivir en la A-453, Palma del Rio (Córdoba). Expediente: C-CO5110/PPR0. Clave: 2-CO-02001.0-0.0-PC 